\title{
An Application of Ocean Wave-Current Refraction to the Gulf Stream Using SEASAT SAR Data
}

\author{
by \\ Michael William Byman \\ B.S., United States Naval Academy (1983) \\ Submitted in partial fulfillment of the \\ requirements for the degree of \\ OCEAN ENGINEER \\ at the \\ MASSACHUSETTS INSTITUTE OF TECHNOLOGY \\ and the \\ WOODS HOLE OCEANOGRAPHIC INSTITUTION
}

August 1989

(C) Michael W. Byman, 1989

The author hereby grants to MIT and WHOI permission to reproduce and to distribute copies of this thesis document in whole or in part.

\footnotetext{
nMan
}

Signature of Author.

Joint Prfuram in Oceanographic Engineering Massachusetts Institute of Technology Woods Hole Oceanographic Institution

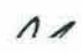
August 11,1989

Certified by

Dr. Hans C. Graber Woods Hole Oceanographic Institution

Thesis Supervisor

Certified by

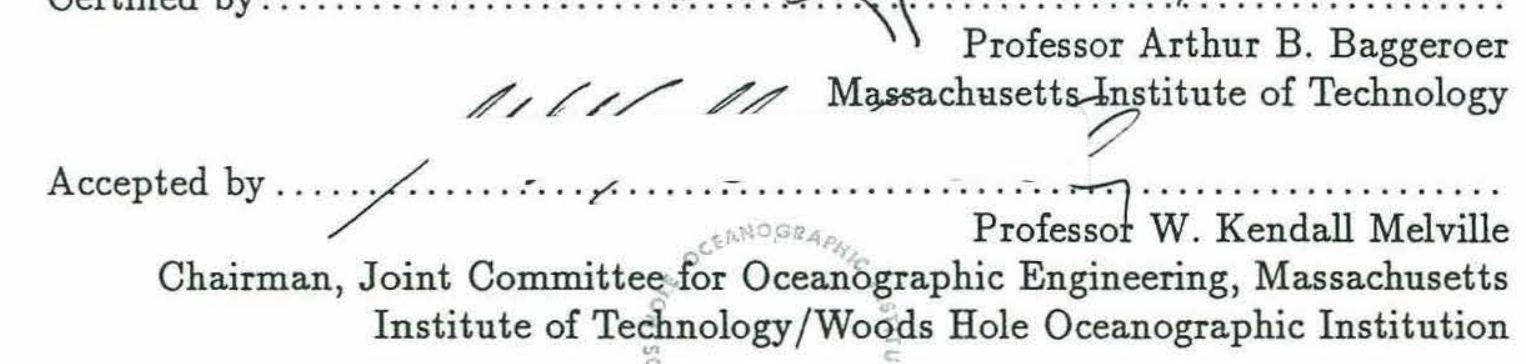




\title{
An Application of Ocean Wave-Current Refraction to the Gulf Stream Using SEASAT SAR Data \\ by \\ Michael William Byman
}

\author{
Submitted to the Massachusetts Institute of Technology- \\ Woods Hole Oceanographic Institution \\ Joint Program in Oceanographic Engineering \\ on August 11,1989, in partial fulfillment of the \\ requirements for the degree of \\ OCEAN ENGINEER
}

\begin{abstract}
When ocean waves in deep water interact with a current, the direction of propagation and characteristics of the waves such as height and length are affected. Swell in the open ocean can undergo significant refraction as it passes through major current systems like the Gulf Stream or Antarctic Circumpolar Current. Remote sensing techniques such as synthetic aperture radars (SAR) have the potential to detect wave systems over a wide geographical area. Combining a model for wave refraction in the presence of currents with SAR measurements, the inverse problem of using the measured wave data can be solved to determine the direction and magnitude of the intervening currents. In this study the behavior of swell measured by SAR on a satellite pass over the Gulf Stream is examined. The refraction predicted by a numerical model under conditions of varying current profiles and velocities is compared to SAR generated wave spectra. By matching the current profile which results in the best correlation of wave refraction to the SAR data, the tomographic problem of measuring the Gulf Stream current is solved.

The best correlation between the model and SAR data is obtained when a current is modeled by a top hat velocity profile with a direction of $75^{\circ}$ and a current speed of $2 \mathrm{~m} / \mathrm{s}$. The direction agrees with that visually observed from the SAR images, and the direction and speeds are close to the Coast Guard estimates for the Gulf Stream at the time of the SEASAT pass. The current profiles used did not take into account a possible widening of the Gulf Stream at the position of the satellite overpass. There is a great deal of scatter in the SAR data, both before and in the Gulf Stream, so it is difficult to correlate every point with specific current behavior, but the increase in wave length and change in wave angle in the center of the Gulf Stream seem to indicate that there may be a non-uniform feature such as the formation of an eddy or other lateral variability near the current's edge.
\end{abstract}

Thesis Supervisor: Dr. Hans C. Graber Woods Hole Oceanographic Institution 


\section{Acknowlegements}

I would like to thank my reasearch advisor Dr. Hans C. Graber for his invaluable guidance in defining and pursuing this research topic. I was supported by the U. S. Navy during my time as a student in the Massachusetts Institute of Technology and Woods Hole Oceanographic Institution Joint Program in Ocean Engineering. 


\section{Contents}

1 Introduction $\quad 10$

1.1 Motivation and Problem Statement . . . . . . . . . . . . 10

1.2 Outline of Present Study . . . . . . . . . . . . . . . 11

2 Theoretical Background 13

2.1 Theory of Wave-Current Interactions . . . . . . . . . . . 13

2.1 .1 Governing Equations . . . . . . . . . . . . . . . . . 13

2.1 .2 Analytical Solutions ... . . . . . . . . . . . 15

2.1 .3 Numerical Solutions . . . . . . . . . . . . . . . . . 18

2.2 Examples of Solutions . . . . . . . . . . . . . . 20

3 SAR Imaging of Ocean Waves 29

3.1 SEASAT . . . . . . . . . . . . . . . . . . . . 29

3.2 Orbit 1339 Images $\ldots \ldots \ldots \ldots \ldots \ldots \ldots \ldots$

4 Case Study: Gulf Stream

4.1 Environmental and Meteorological Conditions During Pass 1339 . . . . . 34

4.2 SAR Data Analysis . . . . . . . . . . . . . . . . 36

4.3 Results. . . . . . . . . . . . . . . . . . . 38

$\begin{array}{lll}5 & \text { Summary and Conclusions } & 61\end{array}$ 


\section{List of Figures}

2-1 Wave ray and orthogonal relationships . . . . . . . . . . . . 14

2-2 Wave orthogonal entering a constant current from still water . . . . . 16

2-3 Wave crest entering a current which has a constant shear . . . . . . . 17

2-4 Ray path along a constant circular arc through a triangle . . . . . . . 19

2-5 Current refraction examples of 10 second waves entering $2 \mathrm{~m} / \mathrm{s}$ currents.

(a) Following current, $\alpha=30^{\circ}$. (b) Opposing current, $\alpha=45^{\circ}$. Note that a heavy line represents the ray path and a thin line the orthogonal path. . 21

2-6 Example of total reflection for a 10 second wave entering a $2 \mathrm{~m} / \mathrm{s}$ following current, $\alpha=55^{\circ}$. Note that a heavy line represents the ray path and a thin line the orthogonal path. . . . . . . . . . . . . 23

2-7 Refraction of 11 second wave entering a following shear current which varies from 0 to $2 \mathrm{~m} / \mathrm{s}, \alpha=60^{\circ}$. (a) Solution generated using Kenyon's analytic result. (b) Solution generated with numerical model. Note that a heavy line represents the ray path and a thin line the orthogonal path. . 24

2-8 Refraction of 11 second wave entering an opposing shear current which varies from 0 to $2 \mathrm{~m} / \mathrm{s}, \alpha=30^{\circ}$. (a) Solution generated using Kenyon's analytic result. (b) Solution generated with numerical model. Note that a heavy line represents the ray path and a thin line the orthogonal path. . 25

2-9 Refraction of 11 second wave entering an opposing shear current which varies from 0 to $2 \mathrm{~m} / \mathrm{s}, \alpha=60^{\circ}$. (a) Solution generated using Kenyon's analytic result. (b) Solution generated with numerical model. Note that a heavy line represents the ray path and a thin line the orthogonal path. . 26 
2-10 Examples of a $\cos ^{2} \phi$ current profile: (a) Wave trapping (20 second wave).

(b) Wave reflection (10 second wave). Note that a heavy line represents the ray path and a thin line the orthogonal path. . . . . . . . . . 27

2-11 Examples of: (a) 5 second wave propagating through a $\cos ^{2} \phi$ current profile. (b) 11.3 second wave propagating through a warm core ring. Note that a heavy line represents the ray path and a thin line the orthogonal

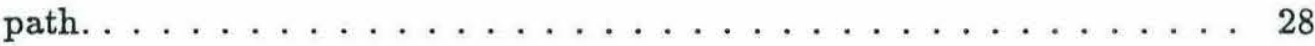

3-1 SEASAT pass 1339 over the North Atlantic (from Beal et al. 1986). . . . 32

3-2 SEASAT pass 1339 over the Gulf Stream (from Beal et al. 1986). . . . . . 33

4-1 Sources of wave systems observed by SEASAT SAR on pass 1339 (from Beal et al. 1986) . . . . . . . . . . . . . . . . . . . . . 35

4-2 (a) Raw FFT of image 20 which is located just after the Gulf Stream. (b) Smoothed FFT (same image as (a)). Satellite travel (azimuth direction)

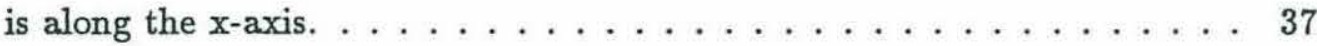

4-3 (a) Wave length and (b) wave angle variation across the Gulf Stream (from Beal et al. 1986). . . . . . . . . . . . . . . . . . . . 39

4-4 Geographical orientation of SEASAT pass 1339 over the Gulf Stream. Numbers at right of track indicate high-resolution SAR image sequence 1 through 22, and numbers at left refer to the two larger $40 \times 40 \mathrm{~km}$ images. 40

4-5 SAR wave spectra: images 1 through $4 \ldots \ldots \ldots$. . . . . . . . 41

4-6 SAR wave spectra: images 5 through 8 . The Gulf Stream edge is located between images 7 and 8 . Note that the energy peak corresponding to the wave system of interest is not evident in image $5 . \ldots$. . . . . . . . . . 42

4-7 SAR wave spectra: images 9 through 12 . Note a $6.7 \mathrm{~km}$ gap occurs between spectra 11 and $12 \ldots \ldots \ldots \ldots$. . . . . . . . . 43

4-8 SAR wave spectra: images 13 through 16 . The North Wall of the Gulf

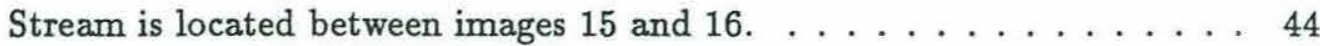

4-9 SAR wave spectra: images 17 through $20 . \ldots \ldots \ldots \ldots$. . . . . . 45

4-10 SAR wave spectra: images 21 and $22 \ldots \ldots \ldots \ldots$. . . . . 46 
4-11 Wave length and direction of wave front crossing the Gulf Stream. The error bars represent the range of possible values along the ridges seen in the spectra in the Gulf Stream. The $\mathrm{x}$-axis is oriented along the east-west direction; the waves are propagating toward the coast. . . . . . . . . . 47

4-12 First $40 \times 40 \mathrm{~km}$ SAR image showing the location of the southern edge of the Gulf Stream (arrow). . . . . . . . . . . . . . . . . . . . 49

4-13 Second $40 \times 40 \mathrm{~km}$ SAR image. The northern boundary (North Wall) of the Gulf Stream is clearly visible in the image (arrow) . . . . . . . . . 50

4-14 Model current profiles: (a) Symmetric jet. (b) Asymmetric jet . (c) Top

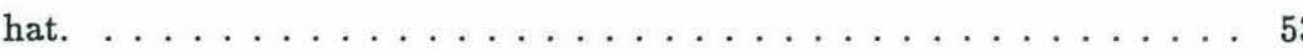

4-15 Refraction of wave rays and orthogonals across symmetric jet current profiles. (a) $U_{\max }$ is $1.5 \mathrm{~m} / \mathrm{s}$ at $65^{\circ}$. (b) $U_{\max }$ is $2.5 \mathrm{~m} / \mathrm{s}$ at $75^{\circ}$. Note that a heavy line represents the ray path and a thin line the orthogonal path. . . 54

4-16 Refraction of wave rays and orthogonals across asymmetric jet current profiles. (a) $U_{\max }$ is $1.5 \mathrm{~m} / \mathrm{s}$ at $60^{\circ}$. (b) $U_{\max }$ is $2.5 \mathrm{~m} / \mathrm{s}$ at $75^{\circ}$. Note that a heavy line represents the ray path and a thin line the orthogonal path. . . . . . . . . . . . . . . 55

4-17 Refraction of wave rays and orthogonals across top hat current profiles. (a) $U_{\max }$ is $1.5 \mathrm{~m} / \mathrm{s}$ at $75^{\circ}$. (b) $U_{\max }$ is $2.0 \mathrm{~m} / \mathrm{s}$ at $60^{\circ}$. Note that a heavy line represents the ray path and a thin line the orthogonal path. . . . . 56

4-18 (a) Symmetric jet profile. (b) Asymmetric jet profile. SAR data $(+)$ superimposed on model output; the waves are propagating toward the coast. The $\mathrm{x}$-axis corresponds to the east-west direction. . . . . . . . . . 57

4-19 (a) Top hat profile with $2 \mathrm{~m} / \mathrm{s}$ current. (b) Top hat profile with $2.25 \mathrm{~m} / \mathrm{s}$ current. SAR data $(+)$ superimposed on model output; the waves are propagating toward the coast. The $\mathrm{x}$-axis corresponds to the east-west

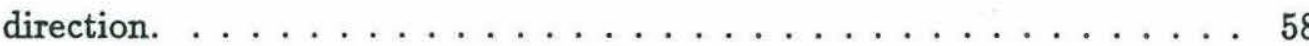




\section{List of Tables}

2.1 Comparison of analytical and numerical results for waves entering a constant current. . . . . . . . . . . . . . . . 22

4.1 Correlations of SAR data vs numerical refraction model for symmetric jet current profile. . . . . . . . . . . . . . . . . . 59

4.2 Correlations of SAR data vs numerical refraction model for asymmetric jet current profile. . . . . . . . . . . . . . . 59

4.3 Correlations of SAR data vs numerical refraction model for top hat current profile. . . . . . . . . . . . . . . . . . 60 


\section{Chapter 1}

\section{Introduction}

\subsection{Motivation and Problem Statement}

When ocean waves in deep water interact with a current, the direction of propagation and characteristics of the waves such as height and length are affected. The influence of currents on wave propagation is more pronounced in deep water, because as the waves shoal, depth refraction dominates the changing wave characteristics. Swell in the open ocean can undergo significant refraction as it passes through major current systems like the Gulf Stream or Antarctic Circumpolar Current. Remote sensing techniques such as synthetic aperture radars (SAR) have the potential to detect wave systems over a wide geographical area. Combining a model for wave refraction in the presence of currents, with SAR measurements, the inverse problem of using the measured wave data can be solved to determine the direction and magnitude of the intervening currents. In this study the behavior of swell measured by SAR on a satellite pass over the Gulf Stream is examined. The refraction predicted by a numerical model under conditions of varying current profiles and velocities is compared to SAR generated wave spectra. Complex correlations are calculated between the vectors formed by SAR measured wave length and direction and the wave length and direction vectors predicted by the numerical model. By chosing the model inputs which result in the best correlation, the tomographic problem of measuring the Gulf Stream current is solved. 
In a pioneering work, Unna (1942) showed how waves are shortened or lengthened by opposing or following currents, respectively. Johnson (1947) derived a form of Snell's law which describes the refraction of wave crests when interacting with a current at an oblique angle to the wave propagation direction. Arthur (1950) introduced the concept of wave energy transmission along rays which are not necessarily perpendicular to the wave crests. Longuet-Higgins and Stewart (1960) demonstrated the importance of nonlinear interactions between waves and currents and introduced the concept of radiation stress to describe the variation of wave energy in the presence of a moving medium. Kenyon (1971) derived an analytical solution for the refraction of orthogonals and rays in the presence of a linear current shear. Abernethy and Gilbert (1975) developed a numerical model to predict the refraction of surface gravity waves over an ocean bottom of varying depth. Treloar (1985) modified this model to include the linear effects of current interactions.

A depth refraction model developed by Brampton (1977) is modified to solve the kinematic problem of wave refraction in currents. This current refraction model is validated by comparing it to analytical solutions derived by Johnson and Kenyon. It is then applied to an ocean situation, and the wave kinematics observed by a synthetic aperture radar flown on SEASAT during a pass over the Gulf Stream are compared to the kinematic behavior predicted by the model.

\subsection{Outline of Present Study}

In section 2 the theory of linear wave interactions with currents is reviewed. The governing equations of wave refraction in the presence of currents are shown, and the derivations of analytical solutions to the refraction of wave fronts passing over a discontinuity, and waves passing into a linear shear current are reviewed. Then the assumptions and structure of the numerical model used in this study are described, and a number of examples are shown comparing analytical and numerical solutions to the problem of wave refraction.

In section 3 the principles of imaging real waves with synthetic aperture radar are reviewed, and the characteristics of the instrument as deployed on SEASAT are described. 
The SEASAT data from pass 1339 used in this study are discussed.

In section 4 the application of SAR data and the numerical model for predicting wave refraction in the presence of a current is applied to the Gulf Stream. First the environmental and meteorological conditions which existed at the time of pass 1339 are presented. Next the analysis of SAR images to produce wave energy spectra is described. Using these spectra, a wave system's propagation is traced across the Gulf Stream. This is compared to the predicted path of wave rays and orthogonals over the Gulf Stream. A number of different possible current profiles for the Gulf Stream are examined. By correlating the predicted wave ray paths and wave lengths with SEASAT measured spectra, a best fit current profile is proposed. 


\section{Chapter 2}

\section{Theoretical Background}

\subsection{Theory of Wave-Current Interactions}

\subsubsection{Governing Equations}

The study of the kinematics of wave-current refraction really involves two problems: (1) the direction of wave propagation, and (2) the changes in wave length. The wave orthogonals (perpendicular to wave crests) follow paths tangent to the wave number vector at a phase speed modified by current interactions. This is the direction of propagation seen by an external observer who takes a 'snapshot' of the wave system. The wave ray gives the direction of energy propagation traveling at the group velocity and is given by the vector sum of the intrinsic group velocity and the current velocity vectors.

The assumptions made in this study in applying the governing equations for wavecurrent interactions are as follows:

1. The effects of viscosity and surface tension are neglected.

2. The fluid is assumed to be incompressible and its motion nearly irrotational.

3. The currents are assumed to be strong and vertically uniform.

4. The spatial and temporal variations of the horizontal currents are assumed to be slow relative to the wave scales; the fluid is deep relative to the wave length (shortwave approximation). 


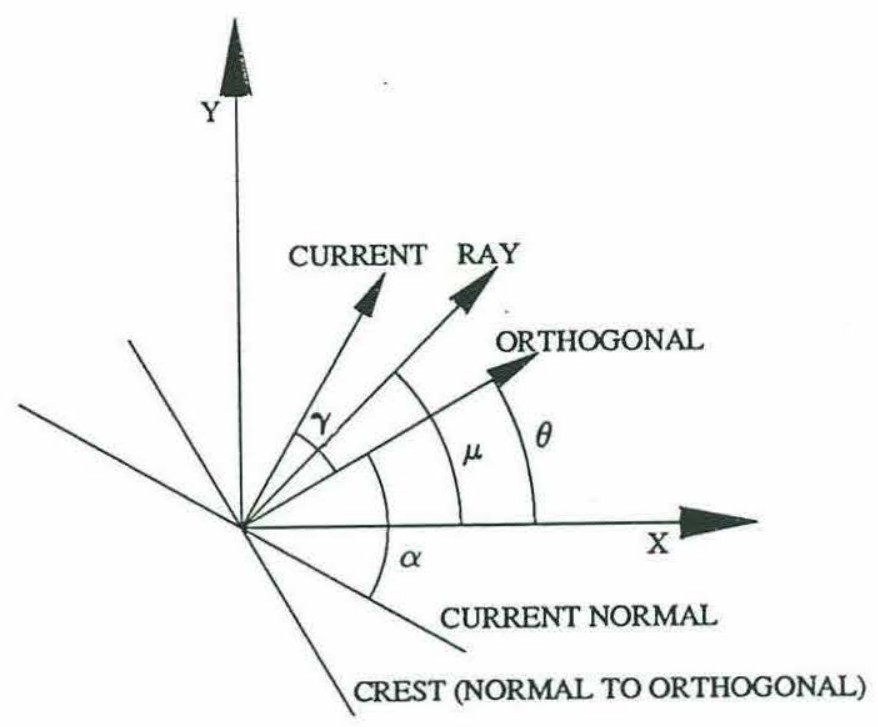

Figure 2-1: Wave ray and orthogonal relationships

5. Reflection and diffraction effects are excluded.

6. The wave amplitude is assumed to be small.

7. Effects by the surface curvature of the earth are small enough to be neglected.

For a steady, inhomogeneous medium, the wave frequency is constant and hence the absolute phase speed $\left(c_{a}\right)$ can be found from the relative or intrinsic frequency $\left(\omega_{r}\right)$, wave number vector $\mathbf{k}$, and current vector $\mathbf{U}$, i.e.,

$$
\begin{aligned}
& \omega_{a}=\omega_{r}+\mathbf{k} \cdot \mathbf{U} \\
& c_{a}=c_{r}+U \sin \alpha
\end{aligned}
$$

where $\alpha$ is the angle between the wave orthogonal (or the wave number vector $\mathbf{k}$ ) and the current normal, as defined in Figure 2-1.

The path of wave orthogonals is determined from integration of the equations:

$$
\begin{aligned}
& \frac{d x}{d s}=\cos \theta \\
& \frac{d y}{d s}=\sin \theta \\
& \frac{d \theta}{d s}=\frac{\sin \theta \frac{\partial c_{a}}{\partial x}-\cos \theta \frac{\partial c_{a}}{\partial y}}{c_{a}}
\end{aligned}
$$


where $c_{a}=\frac{\omega_{a}}{k}$ is the absolute phase speed, as seen by a stationary observer, $\theta$ is the angle between the orthogonal and the $\mathrm{x}$-axis, and an elemental distance along the arc is given by $d s=c_{a} d t$. The relationship between wave crest and current is illustrated in Figure 2-1.

The wave ray path is determined from integration of the ray equations (Kenyon, 1971):

$$
\begin{aligned}
& \frac{d \mathbf{x}}{d t}=\frac{\partial \omega}{\partial \mathbf{k}} \\
& \frac{d \mathbf{k}}{d t}=-\frac{\partial \omega}{\partial \mathbf{x}}
\end{aligned}
$$

Here $\frac{\partial \omega}{\partial \mathbf{k}}$ is the group velocity; $\frac{\partial \omega}{\partial \mathbf{x}}$ describes the change in wave number along rays. Another form of the ray equations (Treloar, 1985) is:

$$
\begin{aligned}
& \frac{d x}{d r}=\cos \mu \\
& \frac{d y}{d r}=\sin \mu \\
& \frac{d \mu}{d r}=\cos ^{2} \mu \frac{d \tan \mu}{d r}
\end{aligned}
$$

where $r$ is now the distance along the ray, and the angle $\mu$ is defined by:

$$
\tan \mu=\frac{c_{g r} \sin \theta+v}{c_{g r} \cos \theta+u}
$$

where $c_{g r}$ is the relative group velocity, $\theta$ is the direction of the wave orthogonal, and $u$ and $v$ are the $x$ and $y$ components of current $\mathrm{U}$. The relationship between the current and wave ray is also shown in Figure 2-1.

\subsubsection{Analytical Solutions}

Two analytical solutions are described here to demonstrate the applicability of these equations. These solutions are used to validate the numerical method outlined in 2.1.3.

\section{Johnson's Derivation of Snell's Law}

Johnson (1947) derived the path of wave orthogonals entering a current from still water. This situation is illustrated in Figure 2-2. The directions of wave crest propagation 


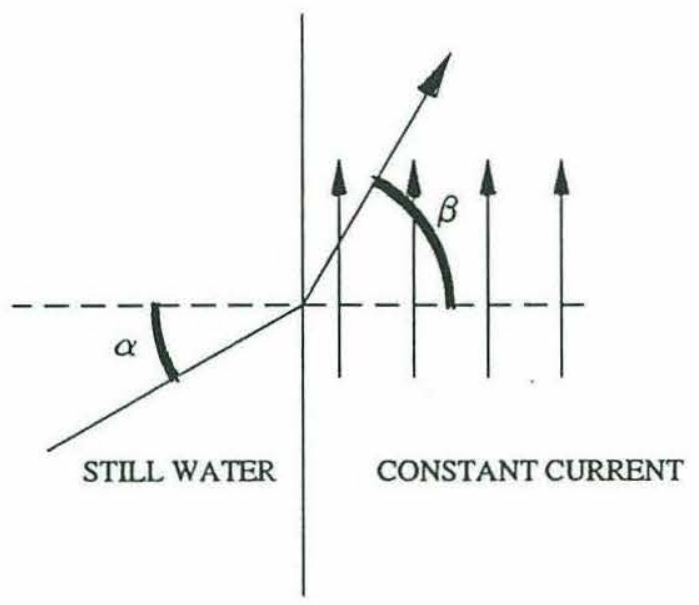

Figure 2-2: Wave orthogonal entering a constant current from still water

and currents are related by the following expression:

$$
\frac{c_{o}}{\sin \alpha}=U+\frac{c}{\sin \beta}
$$

The initial or still water phase velocity is $c_{o}$, and the phase velocity relative to the current is $c$. The waves must be continuous across the discontinuity, so the wave length in still water $L_{o}$ is related to the wave length in the current $L$ :

$$
\frac{L}{\sin \beta}=\frac{L_{o}}{\sin \alpha}
$$

Equation (2.12) can be expressed as:

$$
\sin \beta=\frac{c \sin \alpha}{c_{o}-U \sin \alpha}
$$

Because in deep water phase speed is related to wave length by $c^{2}=\frac{g L}{2 \pi}$, where $g$ is the gravitational constant, (2.13) can be rewritten as:

$$
\frac{c^{2}}{\sin \beta}=\frac{c_{o}^{2}}{\sin \alpha}
$$

A form of Snell's law can be derived from (2.14) and (2.15). Upon simplifying:

$$
\sin \beta=\frac{\sin \alpha}{\left(1-\frac{U}{c_{o}} \sin \alpha\right)^{2}}
$$

The final result (2.16) describes the refraction of wave crests from still water across a current discontinuity. 


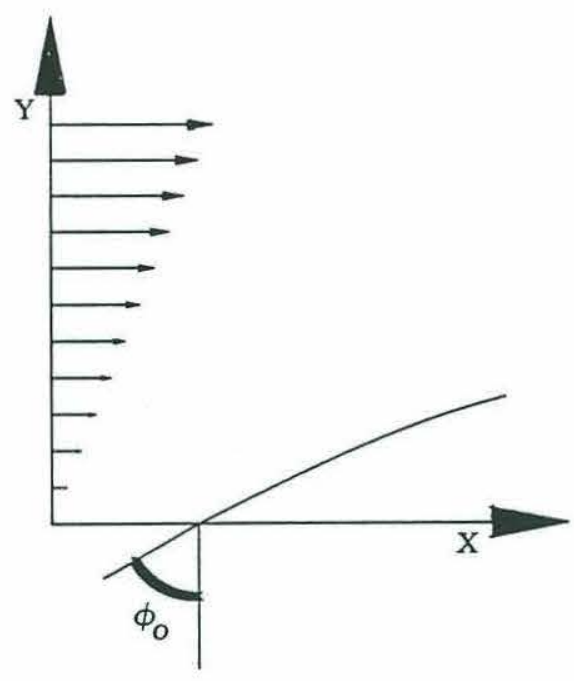

Figure 2-3: Wave crest entering a current which has a constant shear

\section{Kenyon's Solution for the Case of a Linear Shear Current}

Kenyon (1971) used the ray equations to derive an analytical solution to both ray and orthogonal paths for the case of a current with a linear shear. The ray equations hold under the geometrical optics approximation that wave amplitude and frequency vary slowly over distances of the order of the wave length.

An approximate equation for the radius of curvature of the rays is:

$$
R=\frac{c_{g r}}{\xi}
$$

where $\xi=\frac{1}{2}\left(\frac{\partial v}{\partial x}-\frac{\partial u}{\partial y}\right)$, which is the component of vorticity in the positive $z$ direction.

The current velocity is assumed to be in the $\mathrm{x}$-direction and only a function of $\mathrm{y}$; it has a constant shear $s$ :

$$
U(y)= \begin{cases}s y & \text { if } y \geq 0 \\ 0 & \text { if } y<0\end{cases}
$$

The initial conditions are that the rays pass through $x=0, y=0$ at time $t=0$ with initial angle $\phi_{o}=\cot ^{-1} \frac{k_{y o}}{k_{x o}}$. This situation is shown in Figure 2-3.

The integration of the ray equations (2.6-2.7) using the above initial conditions results 
in:

$$
\begin{aligned}
k_{y}\left(t^{\prime}\right) & =k_{x o} t^{\prime} \\
y\left(t^{\prime}\right) & =2 R_{o}\left(\sin \phi_{o}\right)^{-\frac{1}{2}}\left[\left(1+t^{\prime 2}\right)^{\frac{1}{4}}-\left(\sin \phi_{o}\right)^{-\frac{1}{2}}\right] \\
x\left(t^{\prime}\right)= & -y t^{\prime}+\frac{2}{3} R_{o}\left(\sin \phi_{o}\right)^{-\frac{1}{2}}\left\{t^{\prime}\left(1+t^{\prime}\right)^{\frac{1}{4}}-\right. \\
& \left.\cot \phi_{o}\left(\sin \phi_{o}\right)^{-\frac{1}{2}}+2^{-\frac{1}{2}}\left[F(\Theta, K)-F\left(\Theta_{o}, K\right)\right]\right\}
\end{aligned}
$$

where $t^{\prime}=\cot \phi_{0}-s t, F(\Theta, K)$ is the elliptic integral of the first kind, $\cos \Theta=\left(1+t^{\prime 2}\right)^{-\frac{1}{4}}$,

$\cos \Theta_{0}=\left(\sin \phi_{0}\right)^{\frac{1}{2}}$, and $K=2^{-\frac{1}{2}}$. In $(2.20)$ and $(2.21) R_{0}=-\frac{g}{2 s \omega_{0}}$. This is the exact initial radius of curvature of the rays, where $\omega_{0}$ is the initial wave frequency.

Kenyon also showed that Johnson's form of Snell's law can be put in the form $x=x(y)$ for the same shear current by using $\tan \phi=\frac{d x}{d y}$. This results in a description of the wave orthogonals:

$$
x(y)=R_{o}\left(\frac{2}{\sin \phi_{o}}\right)^{\frac{1}{2}}\left[F(\Theta, K)-F\left(\Theta_{o}, K\right)\right]
$$

where $\cos \Theta=\left(\sin \phi_{0}\right)^{\frac{1}{2}}\left(1+\frac{y \sin \phi_{0}}{2 R_{0}}\right)^{-1}$. In Kenyon (1971), $\Theta$ is misdefined as $\cos ^{2} \Theta=$ $\sin \phi_{o}\left(1+\frac{2 y \sin \phi_{o}}{R_{o}}\right)^{-1}$.

\subsubsection{Numerical Solutions}

Over the past four decades numerous graphical and numerical methods have been developed for refraction calculations (see for example, Chao (1972) and Earle and Madsen (1987)). A somewhat different algorithm has been first described by Pararas-Carayannis et al. (1968) and later by Abernethy and Gilbert (1975). Both algorithms are based on triangular grid systems which assume that within each triangle the velocity field is well approximated by a plane. For this condition, the ray path can be solved analytically and in particular, traces out the arc of a circle. There are three major advantages in assuming $\nabla c$ constant within a triangular element over the conventional approach with a rectangular grid. One, an exact solution of (2.5) is possible for triangles but not for rectangular elements. Two, iterative predictor-corrector techniques are usually required to advance the ray in short steps across a rectangular grid element. Three, the ray 


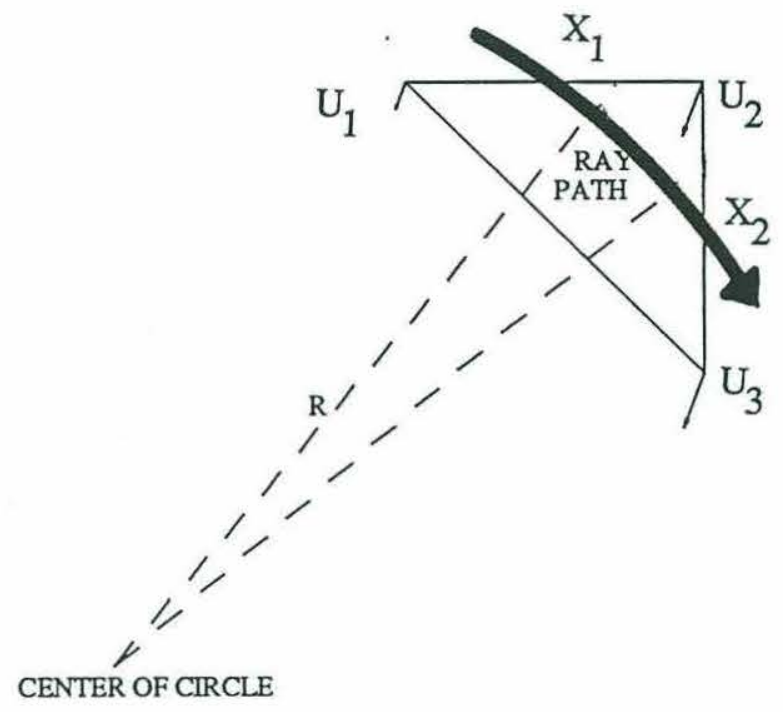

Figure 2-4: Ray path along a constant circular arc through a triangle

path calculations in triangles are much faster because there is no need to specify a time step nor a desired level of accuracy for the iterative procedure. Abernethy and Gilbert (1975) used equilateral triangles in their algorithm. An example of the application of this algorithm can be found in Graber et al. (1989), where the variability of wave kinematics and dynamics due to depth refraction in the North Sea is examined. Brampton (1977) modified Abernethy and Gilberts' algorithm by using right triangles. These elements allow variable grid spacing in the two dimensions and simplify the angular relationships within the triangular grid. A typical triangular element can be seen in Figure 2-4.

For this study the algorithm used by Brampton is further modified to include the effects of currents in deep water. The current field is represented by discrete current vectors at the vertices of triangular elements as seen in Figure 2-4. The orthogonal equations (2.3), (2.4), and (2.5) are applied to the elements. Using (2.16) the absolute 
wave velocity at a point in a current can be calculated from:

$$
c_{a}=\frac{c_{r}}{\left(1-\frac{U}{c_{r}} \cos \gamma\right)^{2}}
$$

where $\gamma$ is the angle between the wave orthogonal and the current shown in Figure 2-1. By inserting a current field with the values specified at each corner of the triangular element, a new phase speed plane can be calculated which includes the current effects. The circular paths traced out correspond to the wave orthogonals.

The calculation of ray trajectories is more complex, since the orthogonal path across each triangle must be computed first. The group velocity at each corner is calculated by taking the phase speed resulting from the wave-current interactions. The absolute group velocity is approximated by adding the current components normal to and along the group velocity vector at each point. In deep water $c_{g}=\frac{1}{2} c$. The entering angle of the ray, $\mu$, must also be calculated for each element.

$$
\begin{aligned}
c_{g a} & =\left[\left(c_{g r}+U \cos \gamma\right)^{2}+(U \sin \gamma)^{2}\right]^{\frac{1}{2}} \\
\mu & =\gamma+\tan ^{-1}\left(\frac{U \sin \gamma}{c_{g r}+U \cos \gamma}\right)
\end{aligned}
$$

Each triangle must be analyzed twice, first to find $\gamma$ from the orthogonal path and then to trace the wave ray.

\subsection{Examples of Solutions}

In order to validate the numerical solution technique described in the previous section, a number of scenarios have been posed in which the numerical solutions can be compared to analytical results.

The simple case first addressed by Johnson (1947) involves the passage of wave systems from still water across a discontinuity into a steady, uniform current. In the figures in this section, the path taken by wave orthogonals are marked by thin lines and the wave rays are shown by thick lines. Table 2.1 compares results from the analytical and numerical solutions. 
(a)

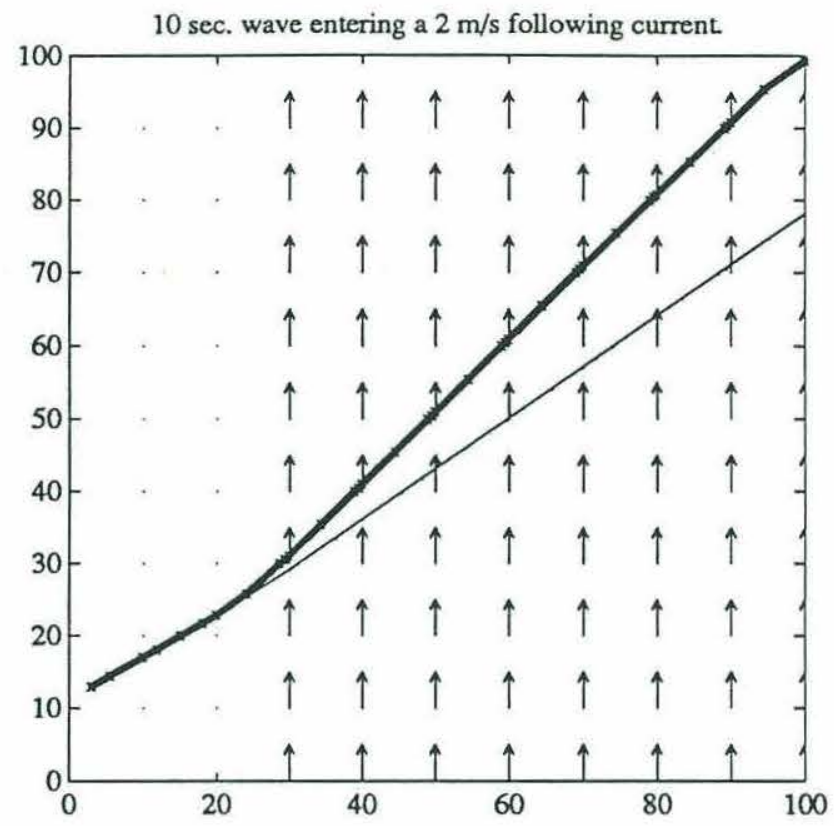

(b)

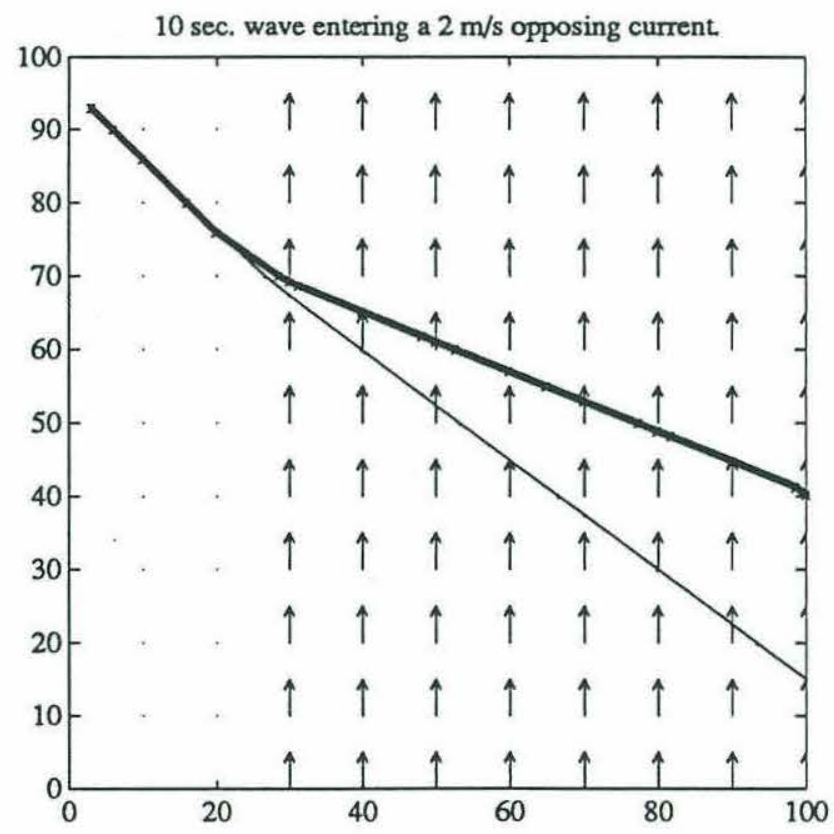

Figure 2-5: Current refraction examples of 10 second waves entering $2 \mathrm{~m} / \mathrm{s}$ currents. (a) Following current, $\alpha=30^{\circ}$. (b) Opposing current, $\alpha=45^{\circ}$. Note that a heavy line represents the ray path and a thin line the orthogonal path. 


\begin{tabular}{|l|l|l|l|l|l|l|}
\hline Figure & $\begin{array}{l}\text { Current } \\
(2 \mathrm{~m} / \mathrm{s})\end{array}$ & $\alpha$ & $\begin{array}{l}\text { Analytical } \\
\text { Orthogonal }\end{array}$ & $\begin{array}{l}\text { Numerical } \\
\text { Orthogonal }\end{array}$ & $\begin{array}{l}\text { Analytical } \\
\text { Ray }\end{array}$ & $\begin{array}{l}\text { Numerical } \\
\text { Ray }\end{array}$ \\
\hline \hline 2-5(a) & Following & $30 .^{\circ}$ & $34.8^{\circ}$ & $35 .^{\circ}$ & $44.6^{\circ}$ & $44.9^{\circ}$ \\
$2-5(\mathrm{~b})$ & Opposing & $315 .^{\circ}$ & $323.5^{\circ}$ & $323.5 .^{\circ}$ & $338.4^{\circ}$ & $337.8^{\circ}$ \\
$2-6$ & Following & $55 .^{\circ}$ & Reflected & Reflected $^{\circ}$ & Reflected & Reflected \\
\hline
\end{tabular}

Table 2.1: Comparison of analytical and numerical results for waves entering a constant current.

A 10 second wave which enters a $2 \mathrm{~m} / \mathrm{s}$ following current at an angle greater than $53^{\circ}$ from the current normal will be reflected. This angle is known as the critical angle. This can also be seen by the solution generated by numerical method in Figure 2-6.

A more complicated situation involves a wave system which enters a current with a linear shear. Figures 2-7 through 2-9 compare the outputs generated by Kenyon's analytical solution with the numerical solution. It can be seen that the analytical solutions are almost identical to the numerical solutions to each problem, validating the results generated by the numerical model.

The numerical solution allows us to examine situations which would involve very complicated analytical solutions. For instance Figures 2-10 and 2-11(a) show the situation of a ring shaped current loop with a $\cos ^{2} \phi$ profile. It can be seen that waves may be trapped, reflected, or simply propagate through such a current system depending upon the angle of incidence.

Another interesting situation is the refraction of a wave field propagating through a large scale eddy such as a warm core ring often found near the Gulf Stream. The modeling of such a warm core ring has been described in Mapp et al. (1985). The flow field used to simulate this large eddy was a steady circular jet. The radial profile of tangential velocity is a power function joined to a Gaussian. This example can be seen in Figure 2-11(b). Orthogonals which penetrate into the center of the warm core ring were refracted, but not greatly. Orthogonals which grazed the left side of the ring were reflected; they essentially entered a following current at greater than the critical angle. One orthogonal which entered the right side of the ring became trapped in an opposing current and was refracted almost $90^{\circ}$. 


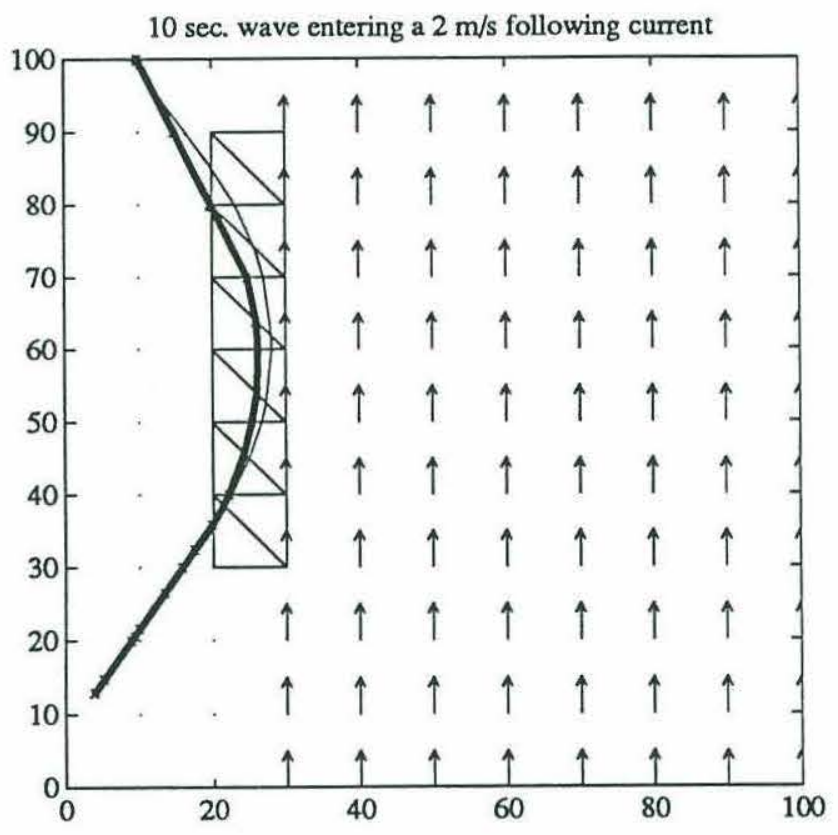

Figure 2-6: Example of total reflection for a 10 second wave entering a $2 \mathrm{~m} / \mathrm{s}$ following current, $\alpha=55^{\circ}$. Note that a heavy line represents the ray path and a thin line the orthogonal path. 
(a)

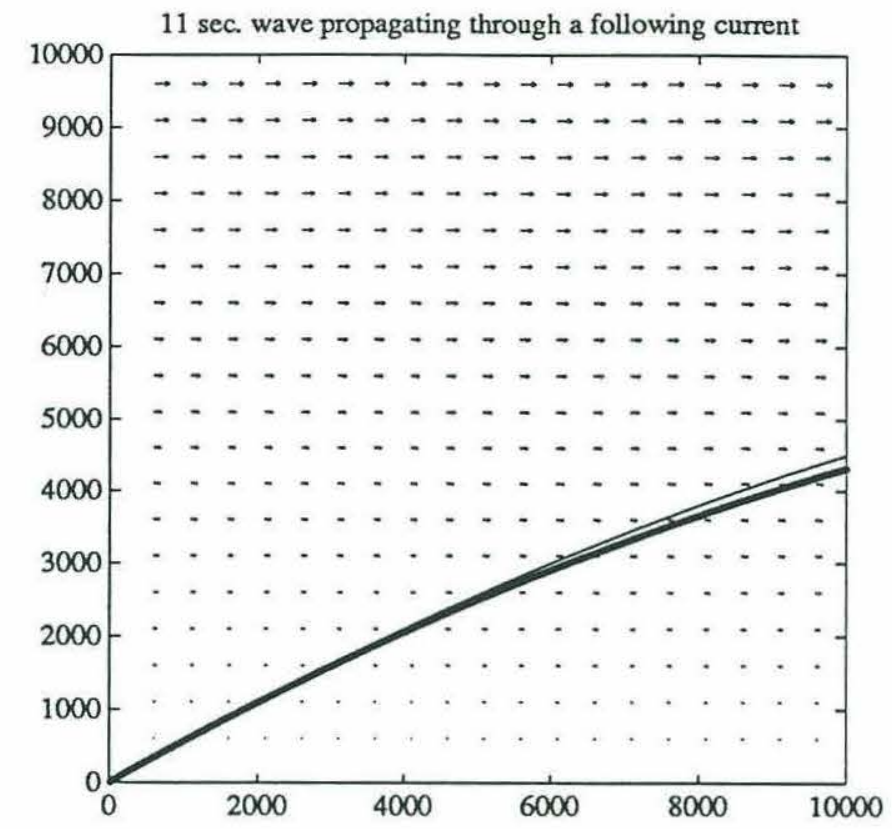

(b)

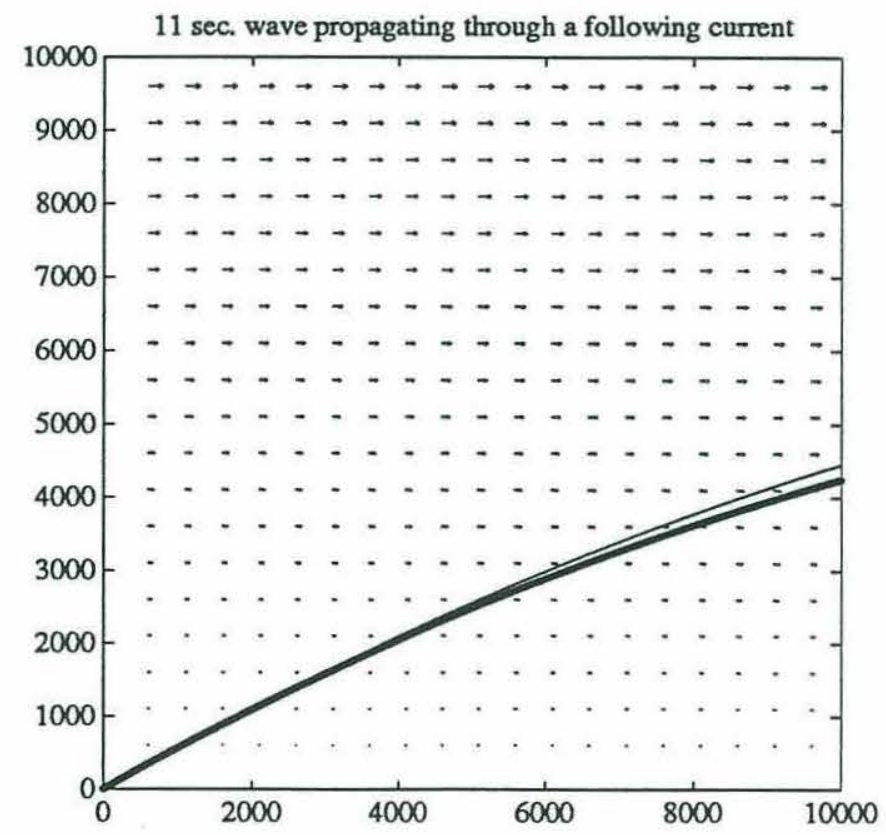

Figure 2-7: Refraction of 11 second wave entering a following shear current which varies from 0 to $2 \mathrm{~m} / \mathrm{s}, \alpha=60^{\circ}$. (a) Solution generated using Kenyon's analytic result. (b) Solution generated with numerical model. Note that a heavy line represents the ray path and a thin line the orthogonal path. 
(a)

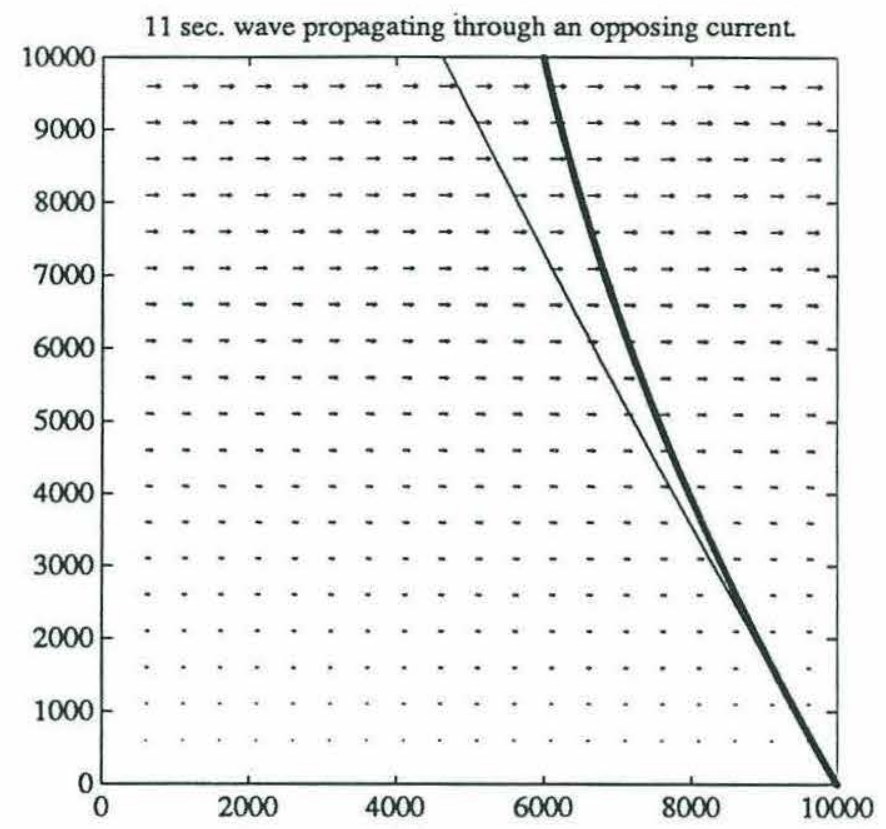

(b)

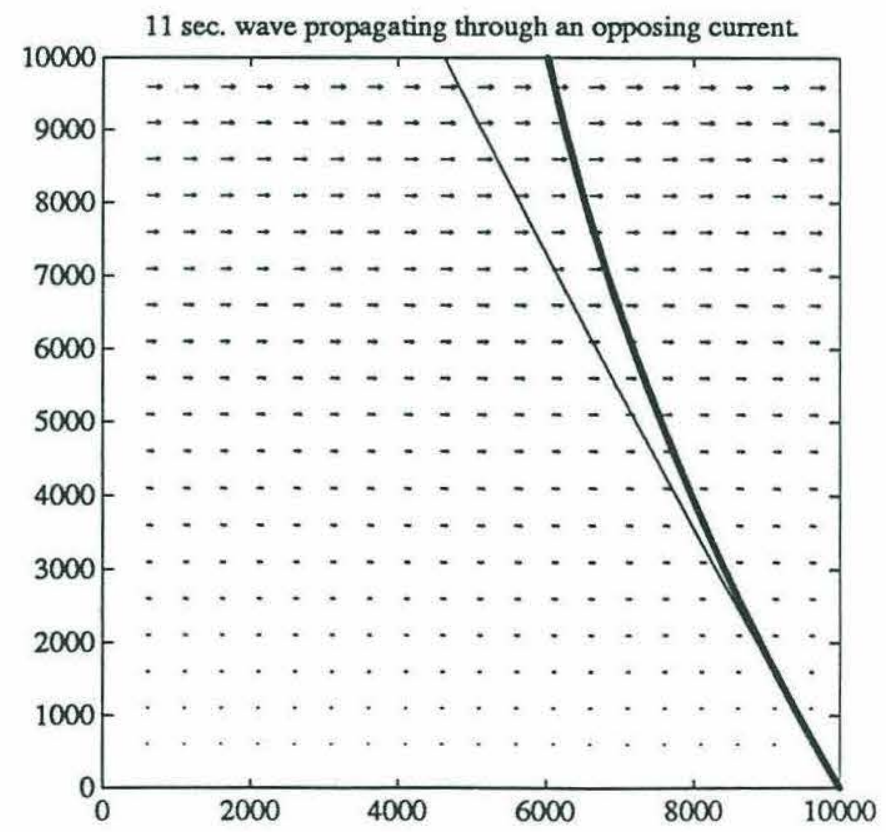

Figure 2-8: Refraction of 11 second wave entering an opposing shear current which varies from 0 to $2 \mathrm{~m} / \mathrm{s}, \alpha=30^{\circ}$. (a) Solution generated using Kenyon's analytic result. (b) Solution generated with numerical model. Note that a heavy line represents the ray path and $a$ thin line the orthogonal path. 
(a)

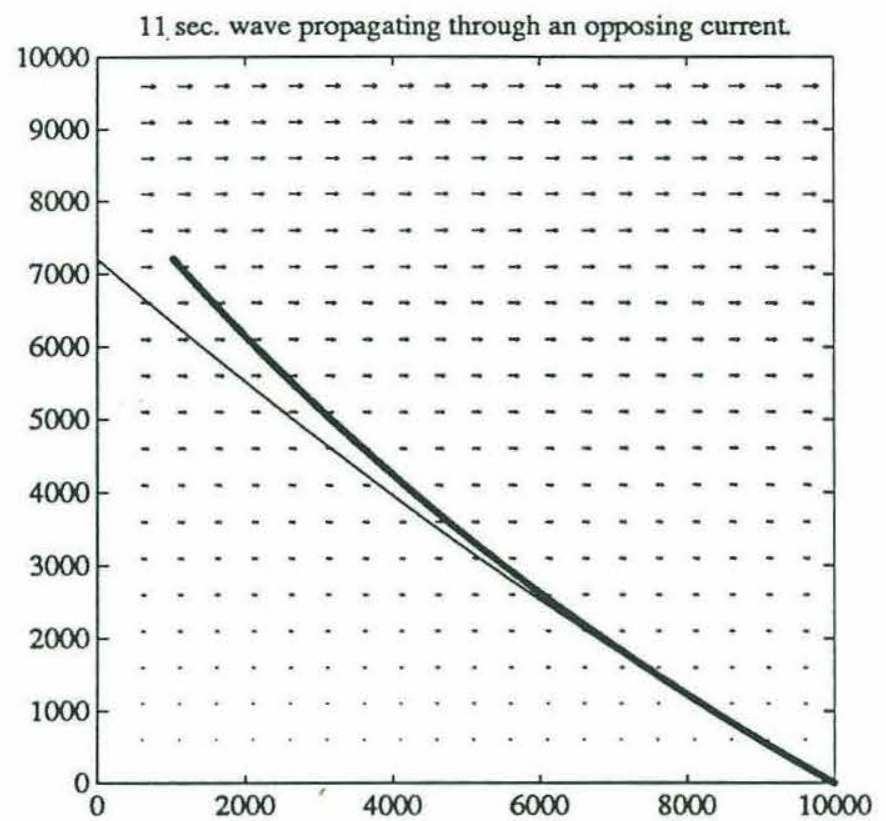

(b)

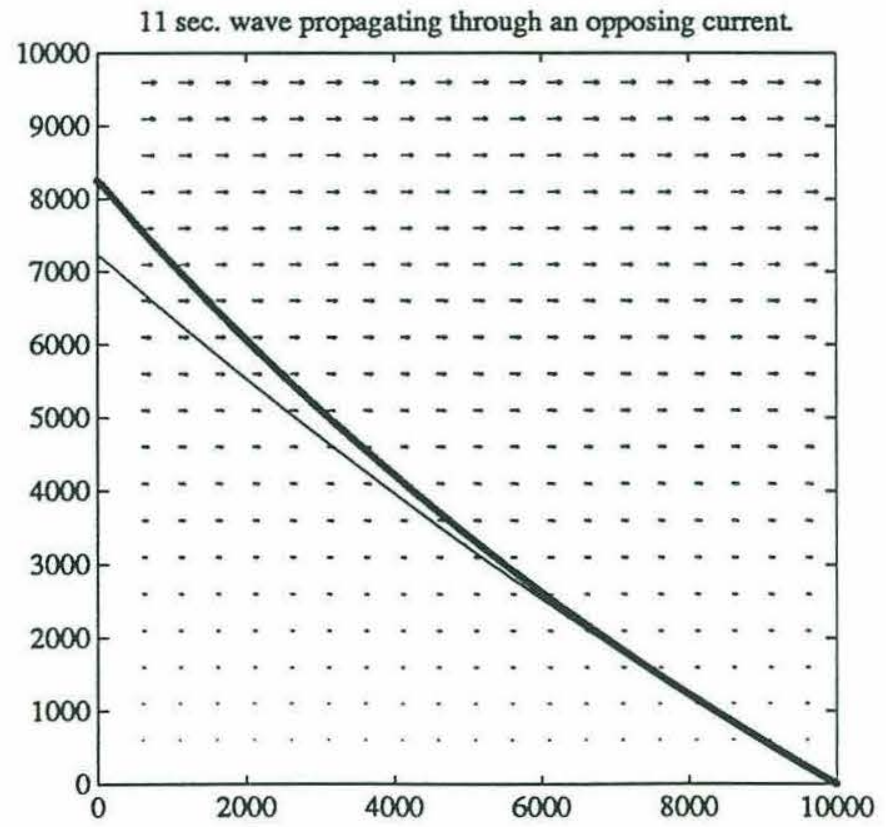

Figure 2-9: Refraction of 11 second wave entering an opposing shear current which varies from 0 to $2 \mathrm{~m} / \mathrm{s}, \alpha=60^{\circ}$. (a) Solution generated using Kenyon's analytic result. (b) Solution generated with numerical model. Note that a heavy line represents the ray path and a thin line the orthogonal path. 
(a)

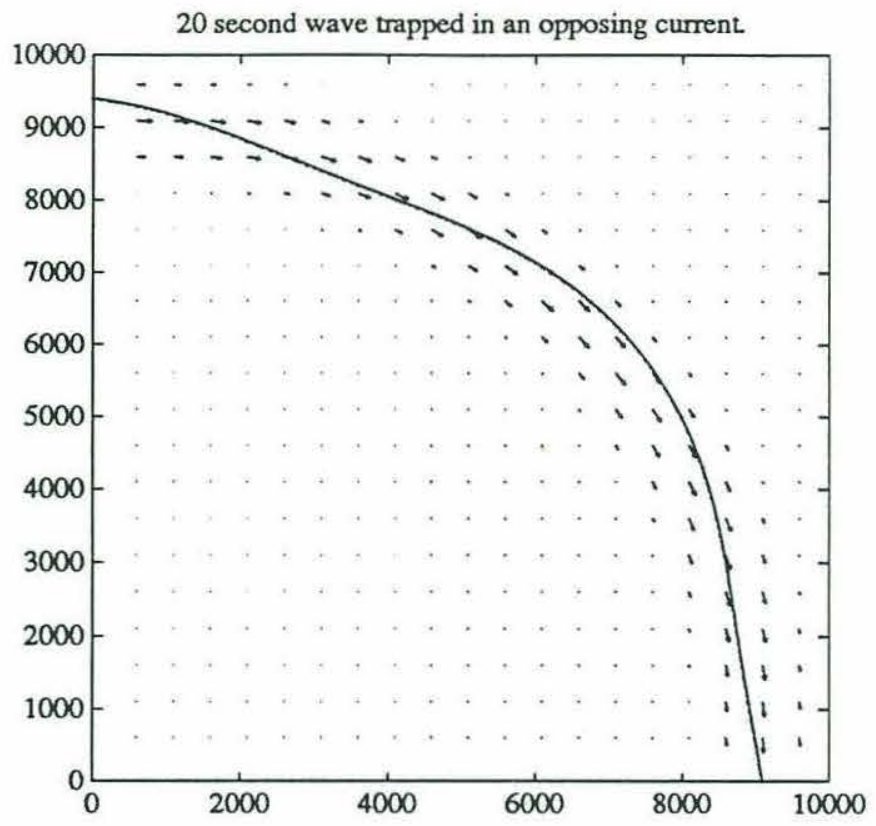

(b)

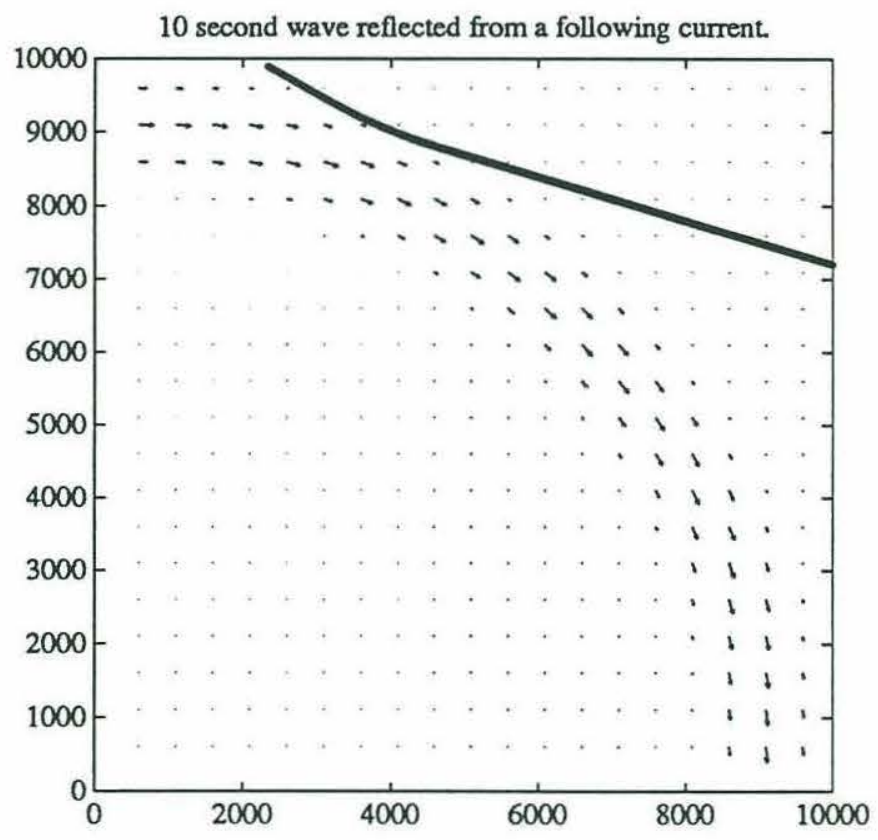

Maximum current is $2 \mathrm{~m} / \mathrm{s}$, current profile is cos squared function.

Figure 2-10: Examples of a $\cos ^{2} \phi$ current profile: (a) Wave trapping (20 second wave). (b) Wave reflection (10 second wave). Note that a heavy line represents the ray path and a thin line the orthogonal path. 
(a)

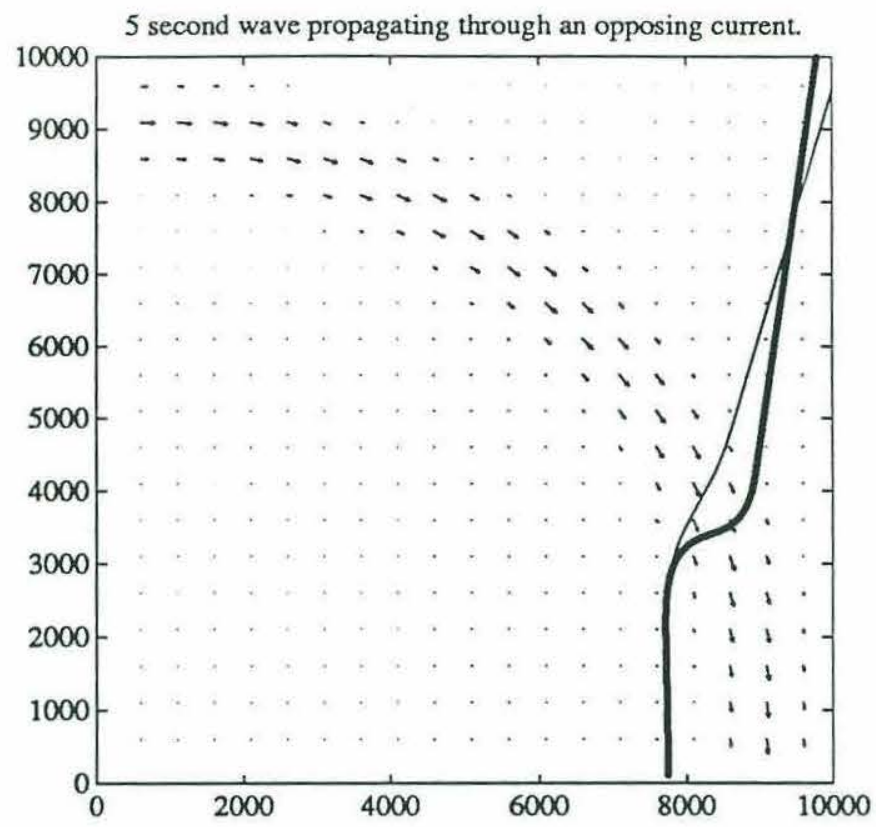

Maximum current $2 \mathrm{~m} / \mathrm{s}$, current profile is a cos squared function.

(b)

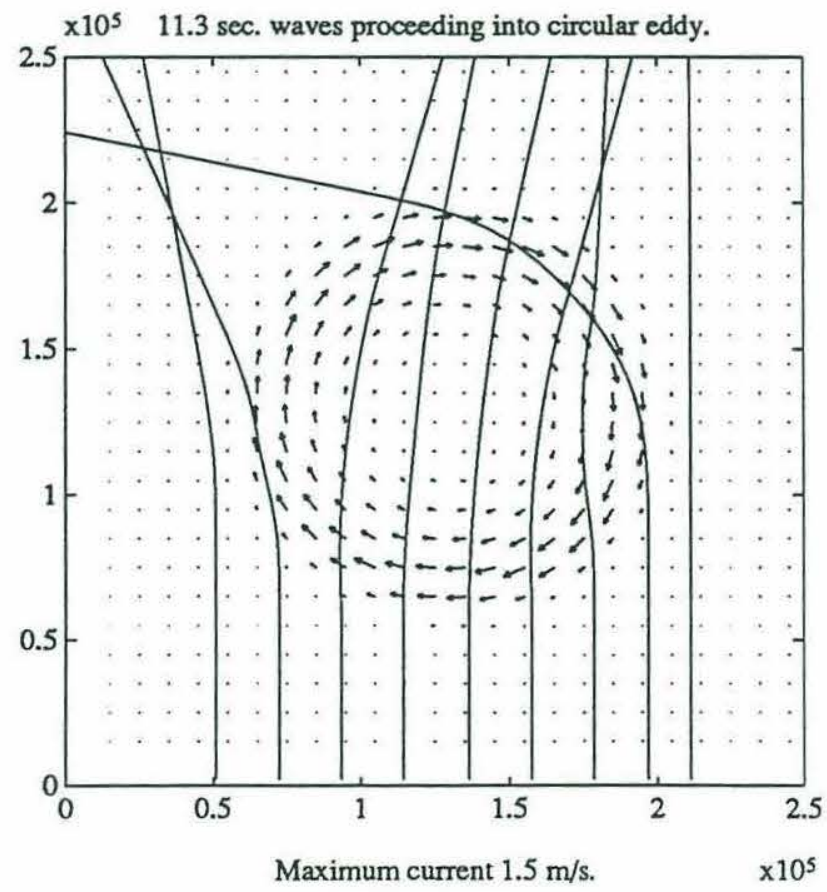

Figure 2-11: Examples of: (a) 5 second wave propagating through a $\cos ^{2} \phi$ current profile. (b) 11.3 second wave propagating through a warm core ring. Note that a heavy line represents the ray path and a thin line the orthogonal path. 


\section{Chapter 3}

\section{SAR Imaging of Ocean Waves}

\subsection{SEASAT}

One of the instruments deployed on the oceanographic research satellite SEASAT was a synthetic aperture radar. This microwave sensor artificially synthesizes an aperture or antenna which is hundreds of meters long in space. Therefore, a fine spatial resolution of about $20 \mathrm{~m}$ can be obtained even from altitudes of $800 \mathrm{~km}$. The basic imaging response of a SAR to the ocean surface is explained by Bragg scattering from short gravity waves. In the case of radars in the frequency range of SEASAT SAR $(1.27 \mathrm{GHz}$, or the LBand), the Bragg waves are of the order of $20 \mathrm{~cm}$. The Bragg waves, which are formed by local winds, are superimposed on underlying long (greater than fifty meter) waves which modulate the Bragg waves. Thus, the Bragg waves allow the SAR imaging of the longer waves. This implies that one requirement for SAR imaging of ocean swell is a local wind field sufficiently strong to create these waves of about $20 \mathrm{~cm}$ length.

One potential use oceanographers see for SAR is in the collection of directional ocean wave spectra. Kinsman (1965) and Phillips (1980) have shown that the directional wave energy spectrum is probably the most complete single descriptor of the ocean surface. When the only source of these spectra is from local measurements taken from bouys or ships, their use to oceanographers who seek to understand large scale ocean processes is limited. Remote sensing using SAR promises to provide a valuable tool to better 
understand the ocean environment.

The resolution obtained by SAR consists of range resolution (ground resolution perpendicular to the satellite trajectory) and azimuth resolution (ground resolution in the direction of the satellite trajectory).

The range resolution, $\delta y$, is obtained by the pulse length, $\delta r$, projected onto the surface.

$$
\delta y=\frac{\delta r}{2 \sin \epsilon}=\frac{c \tau}{2 \sin \epsilon}
$$

where $c$ is the velocity of light, $\tau$ is the pulse duration, and $\epsilon$ is the incidence angle.

The azimuthal resolution $\delta x$ is linked to the accuracy in determining the Doppler shift of the backscattered signal. A series of pulses are transmitted by the radar; these are sampled along the radar trajectory, the synthesized aperture. For a stationary target, the azimuthal resolution only depends on the size of the real antenna.

$$
\delta x=\frac{D}{2}
$$

where $\mathrm{D}$ is the real antenna length.

The imaging of waves by SAR is influenced by three effects. These are: (1) tilt modulation, (2) hydrodynamic interactions, and (3) motion effects (velocity bunching and azimuthal image smearing). These are discussed in Monaldo and Lyzenga (1986) and in Graber and Kelly (1988). Tilt modulation is a geometric effect which results from the different incidence angles of Bragg scattering waves seen by the radar as they propagate over longer waves. The hydrodynamic effect is characterized by modulations in power caused by changes in the spectral density at the Bragg wave number across the profile of the long waves. Hydrodynamic modulations result from long wave-short wave interactions which increase the ripple amplitude near swell crests and decrease the ripple height near swell troughs. They also come from the distortion of the airflow above the sea surface by swell waves. These effects are environmentally dependent and generally not well understood. Velocity bunching causes image degradation due to the movement of the sea surface resulting from the orbital velocities of long waves. The rising face of the wave is shifted on the image in the direction of flight, while the falling face is shifted opposite the flight direction. For waves traveling in range, this has no imaging effect. 
However, waves propagating in the azimuth direction are affected significantly. Similar effects caused by waves shorter than the azimuthal resolution dimension cause Doppler smearing.

The combination of these two effects creates a limitation faced by all SARs viewing the ocean: a degradation of the wave energy spectrum in the azimuth direction. The degradation is particularly pronounced in high flying SARs such as the one deployed on SEASAT. Azimuthal smearing limits the usefulness of SEASAT data in studying the refraction of wave systems across currents. As is discussed in section 4.3 , the wave system examined in this case study is refracted from range into azimuth. This fact made it difficult to track the wave system across the Gulf Stream.

\subsection{Orbit 1339 Images}

The synthetic aperture radar deployed on SEASAT had a lifetime of only about three months. There are a limited number of satellite passes which had interesting wind and wave conditions along with independent measures of these parameters. Pass 1339 of September 28, 1978 was one such pass.

Beal et al. (1983) and (1986) reported on the processing of the SAR images and the oceanographic conditions along the entire pass. The present study focuses on the portion of the pass in the vicinity of the Gulf Stream. Figures 3-1 and 3-2 which appeared in Beal et al. (1986) show the geographic orientation of pass 1339.

Digitally processed SAR data from MacDonald Dettwiler and Associates consisting of $40 \times 40 \mathrm{~km}$ images were used for the analysis here. A description of the processing of these images is included in Chapter 4. 


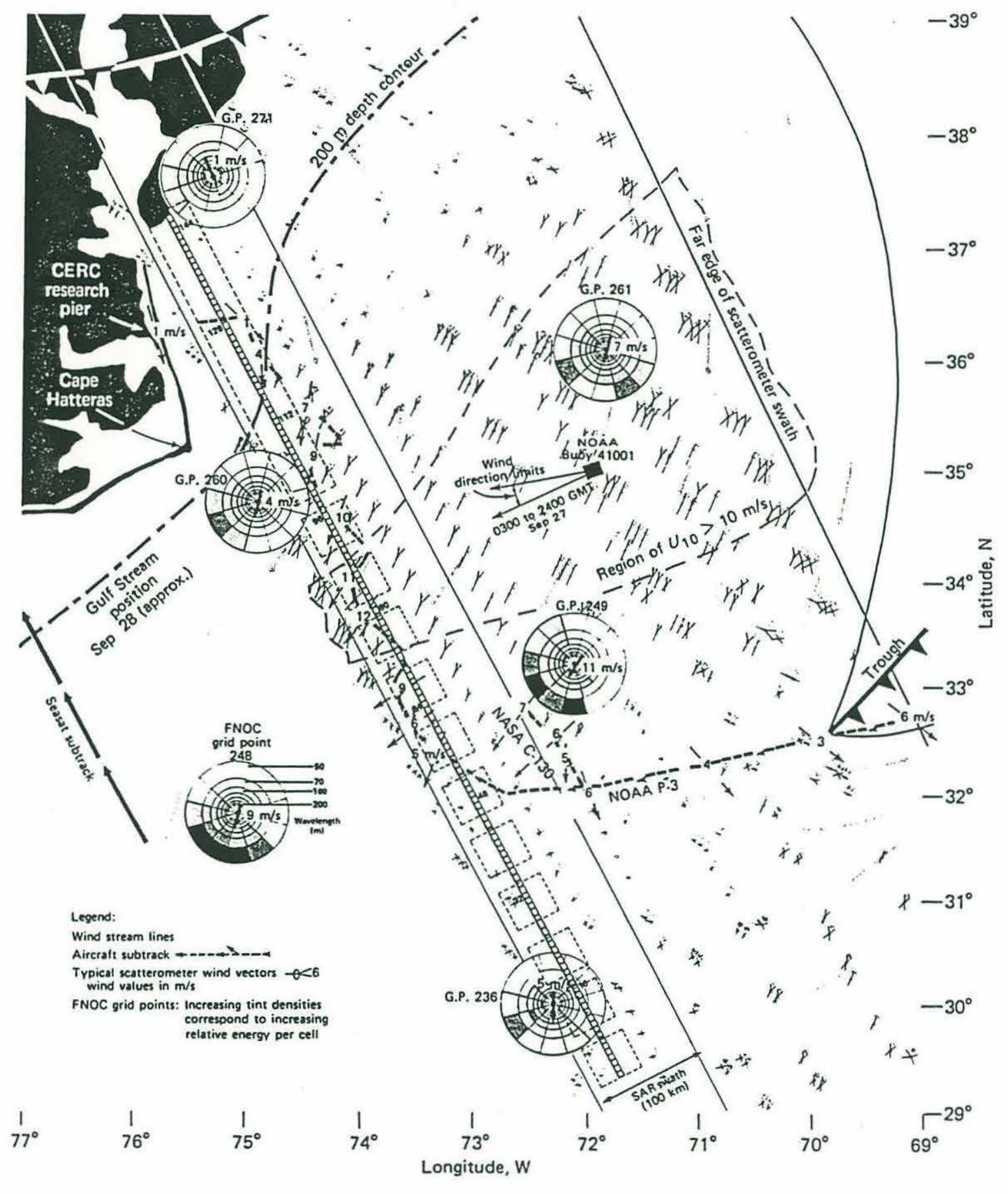

Figure 3-1: SEASAT pass 1339 over the North Atlantic (from Beal et al. 1986). 


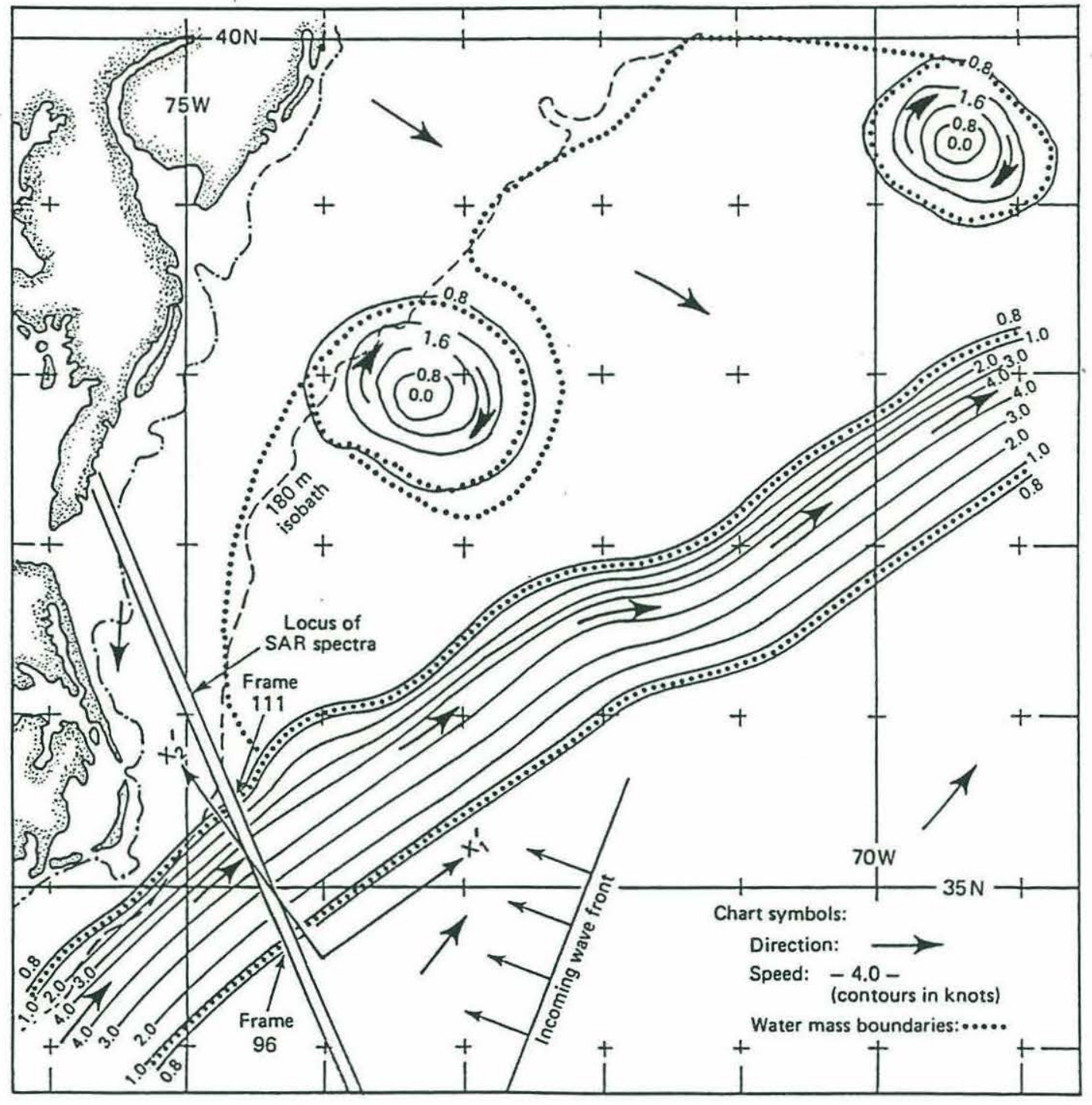

Figure 3-2: SEASAT pass 1339 over the Gulf Stream (from Beal et al. 1986). 


\section{Chapter 4}

\section{Case Study: Gulf Stream}

\subsection{Environmental and Meteorological Conditions Dur- ing Pass 1339}

SEASAT pass 1339 crossed the Gulf Stream on September 28, 1978 at 1521 GMT. Two dominant wave systems existed throughout most of the $900 \mathrm{~km}$ pass. The primary system consisted of $200 \mathrm{~m}$ swell which propagated from southeast to northwest; a secondary system of $100 \mathrm{~m}$ waves was more variable in direction, but generally traveled between a westerly to southwesterly direction.

Beal et al. (1986) demonstrated that the primary system originated in Tropical Depression 12 on September 24. The maximum winds in the vicinity of the depression were estimated at $20 \mathrm{~m} / \mathrm{s}$ and generated waves which traveled towards the west. This wave source can be seen in Figure 4-1.

A smaller storm closer to the satellite pass developed on 26 and 27 September. The

peak winds were estimated at $15 \mathrm{~m} / \mathrm{s}$. This storm can also be seen on Figure 4-1 and is the source of the secondary $100 \mathrm{~m}$ wave system.

In the immediate vicinity of the satellite pass, a weak trough dominates the local wind field causing a counter clockwise wind movement over the $900 \mathrm{~km}$ length of the satellite pass. The wind is southerly with a speed of about $5 \mathrm{~m} / \mathrm{s}$ over the Gulf Stream. The wind vectors are shown in Figure 3-1. 


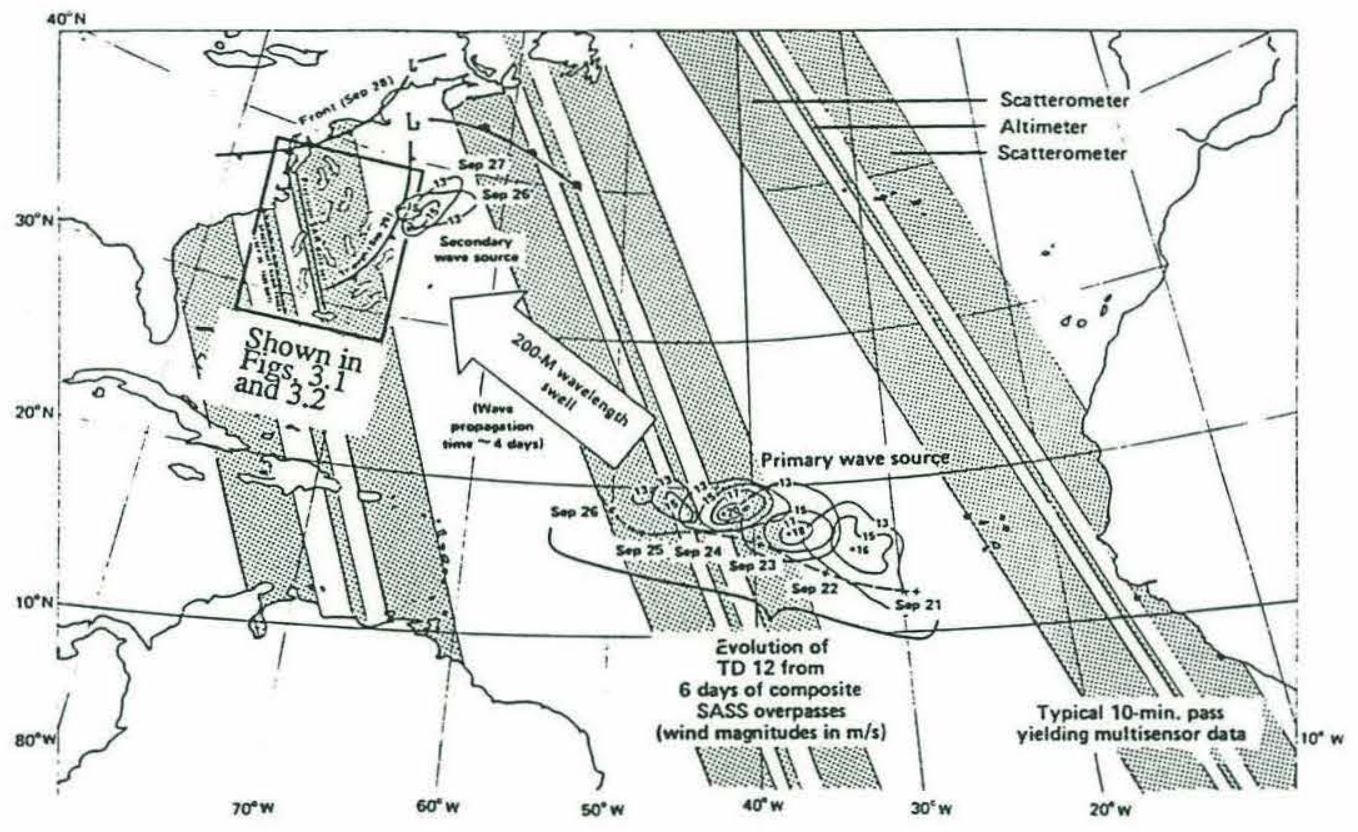

Figure 4-1: Sources of wave systems observed by SEASAT SAR on pass 1339 (from Beal et al. 1986). 


\subsection{SAR Data Analysis}

The available set of SAR data from pass 1339 consists of nineteen $40 \times 40 \mathrm{~km}$ images digitally processed by MacDonald Dettwiler and Associates (Vanvouver, Canada). Beal et al. (1983) and (1986) looked at the entire pass to follow the propagation of the 200 m swell system. In the current study, only the two $40 \mathrm{~km}$ images which span the Gulf Stream are re-examined in a detailed analysis of the wave-current interactions, as the $200 \mathrm{~m}$ swell system enters the flow of the Gulf Stream at an oblique angle and undergoes refraction.

From each of the two images, eleven frames of size $512 \times 512$ pixels were defined. These provided overlapping images of $6.4 \times 6.4 \mathrm{~km}$ on a side. Each of the twenty-two frames thus defined overlaps the next by about $3 \mathrm{~km}$ with the exception of the first and last in each of the large images.

The data from each frame is normalized by subtracting the mean value of the frame from each pixel value within the frame and then dividing by the mean. A two dimensional fast Fourier transform is performed on each of the resulting normalized data frames. The complex transform is multiplied by its complex conjugate and oriented with the zero wave number value in the center. The resulting transform contains information out to $\frac{2 \pi}{25} \frac{\mathrm{rad}}{\mathrm{m}}$. The image is then trimmed to $272 \times 272$ pixels. An example of a raw Fourier transform is shown in Figure 4-2.

The transforms are spectrally smoothed using a discrete $15 \times 15$ pixel Gaussian function. Following Beal et al. (1986), the smoothed spectrum $S_{\&}$ is related to the raw spectrum $S_{u}$ by:

$$
S_{s}\left(k_{x}, k_{y}\right)=\frac{\sum_{m=-7}^{+7} \sum_{l=-7}^{+7} S_{u}\left(k_{x+m}, k_{y+l}\right) e^{-\frac{m^{2}+l^{2}}{25}}}{\sum_{m=-7}^{+7} \sum_{l=-7}^{+7} e^{-\frac{m^{2}+l^{2}}{25}}}
$$

The effect of the smoothing kernel (4.1) on the raw spectrum is also shown in Figure 42. In this and following figures showing contour plots, adaptive contour intervals were used to highlight energy peaks of interest. The interior of the $256 \times 256$ pixel smoothed region represent wave lengths greater than $50 \mathrm{~m}$.

The spectra could be further smoothed by along-track averaging of several adjacent 
(a) Unsmoothed Spectrum

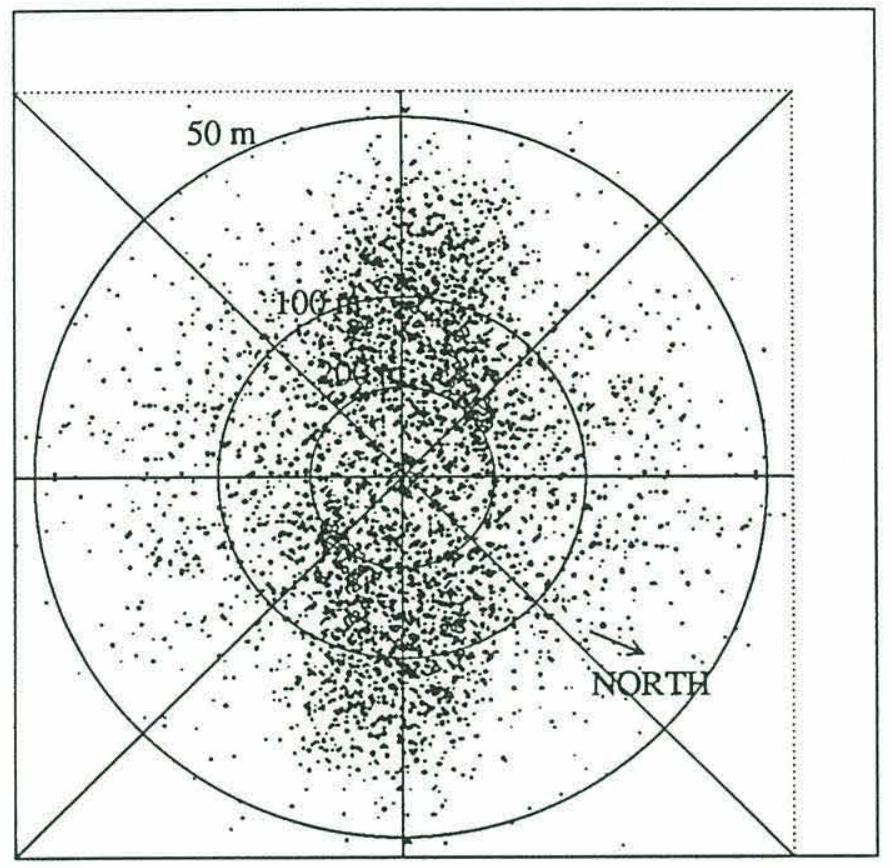

(b)

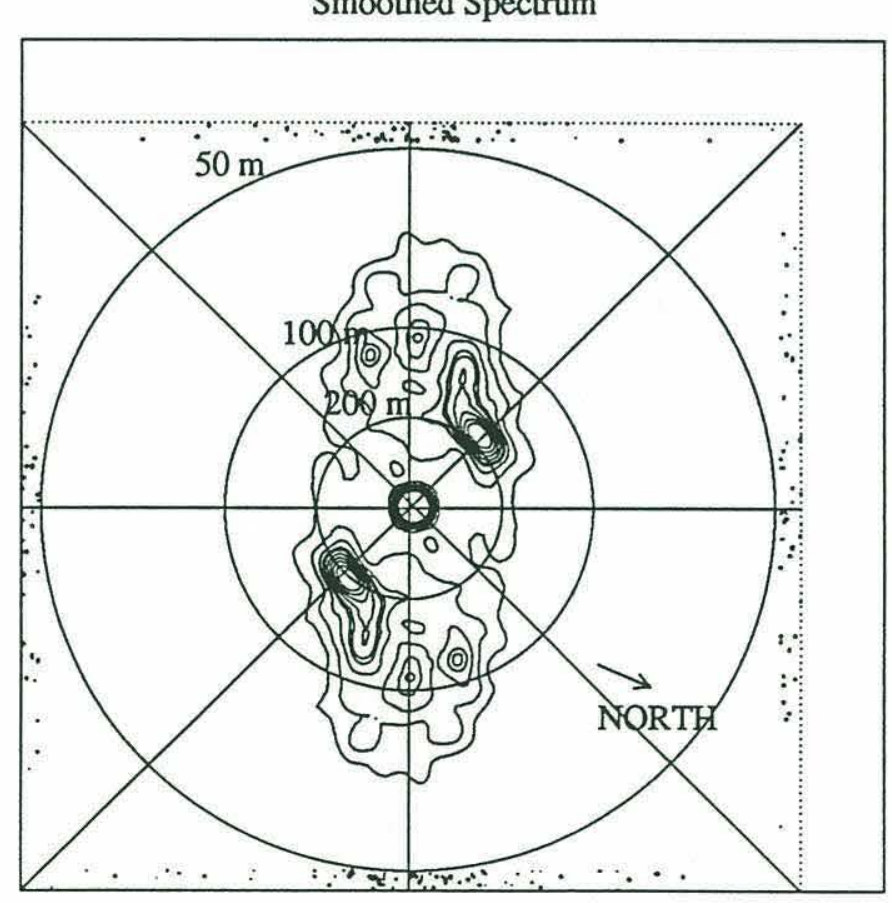

Figure 4-2: (a) Raw FFT of image 20 which is located just after the Gulf Stream. (b) Smoothed FFT (same image as (a)). Satellite travel (azimuth direction) is along the $x$-axis. 
spectra, but this is inappropriate over a region of rapidly changing conditions such as the Gulf Stream.

\subsection{Results}

Beal et al. (1986) processed six $6.4 \times 6.4 \mathrm{~km}$ spectra from each $40 \times 40 \mathrm{~km}$ SAR image. As they followed what appeared to be the dominant $200 \mathrm{~m}$ wave system across the Gulf Stream, they observed a wave shortening resulting in a wave number increase four times that which their model predicted. The wave number vector seemed to turn into the current, contrary to the behavior predicted by Snell's law. Beal et al. concluded that it is possible that the system they traced may actually be a secondary system inside the Gulf Stream. Figure 4-3 shows the wave length and angle of the system which Beal et al. traced across the Gulf Stream. The wave length behaved approximately as expected for a wave which was propagating into an opposing current at an oblique angle, but the direction turned in the wrong sense.

In this study a closer spacing of wave spectra is used to allow trends to be better seen in the rapidly changing environment of the Gulf Stream. It can be seen that merely chosing the highest energy spectral peak does not ensure that the correct system is always observed during the wave system's propagation through the Gulf Stream. Figure 4-4 show the geographical orientation of the SEASAT SAR images from pass 1339 which were processed into the twenty-two spectra. Figures 4-5 through 4-10 display these spectra. The energy peak of the $200 \mathrm{~m}$ wave system is marked on each figure. It can be seen that azimuthal smearing makes the determination of this peak difficult inside the Gulf Stream. The wave lengths and direction of these peaks are plotted on Figure 411. The shortening and refraction of the wave system toward the North inside the Gulf Stream is visible. These results suggest that Beal et al. did apparently trace the wrong system through the Gulf Stream.

It can be seen from Figure 4-11 that the wave length of the wave system across the Gulf Stream is shortened from $200 \mathrm{~m}$ to about $170 \mathrm{~m}$. At a $40^{\circ}$ incidence angle between the wave front and the Gulf Stream normal, a $200 \mathrm{~m}$ wave should be shortened to $175 \mathrm{~m}$ 
(a)

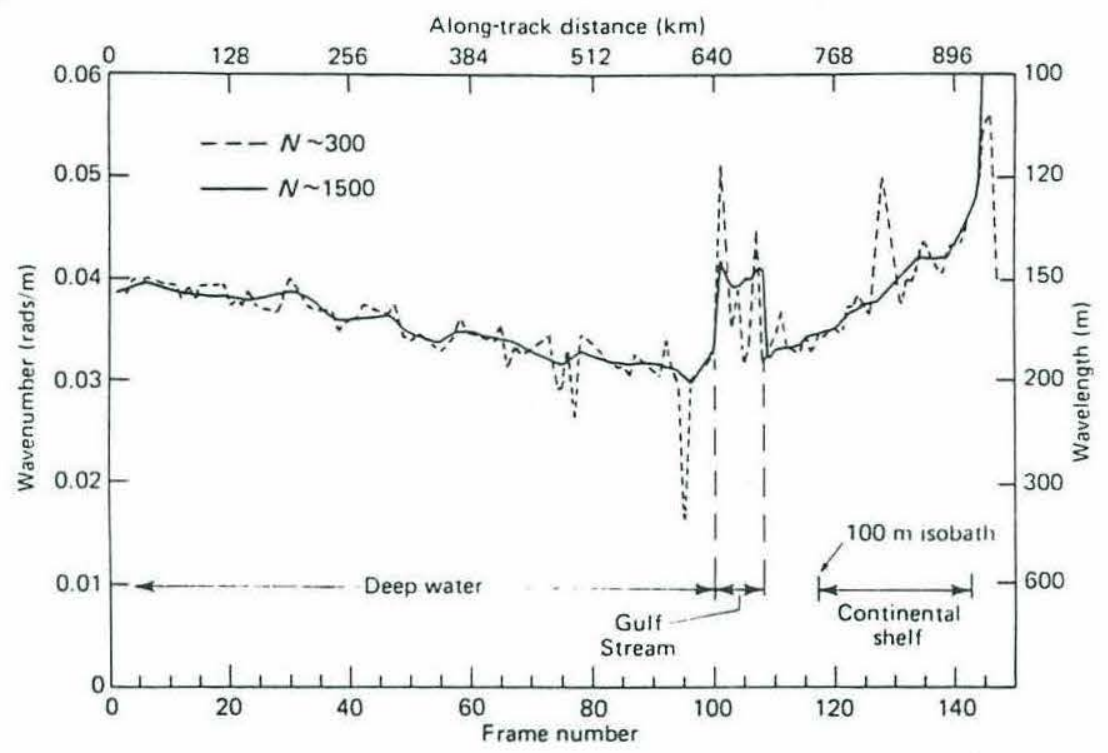

(b)

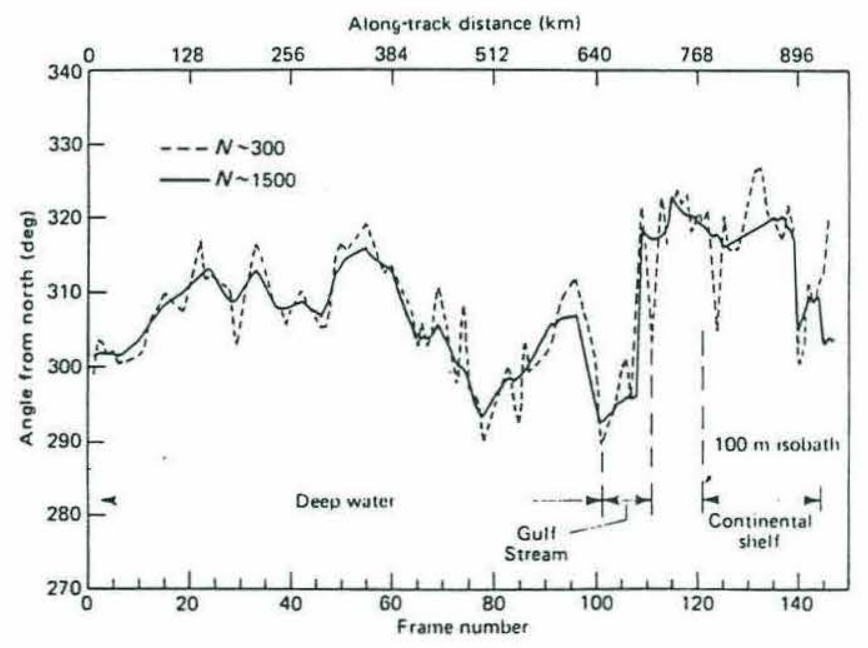

Figure 4-3: (a) Wave length and (b) wave angle variation across the Gulf Stream (from Beal et al. 1986). 


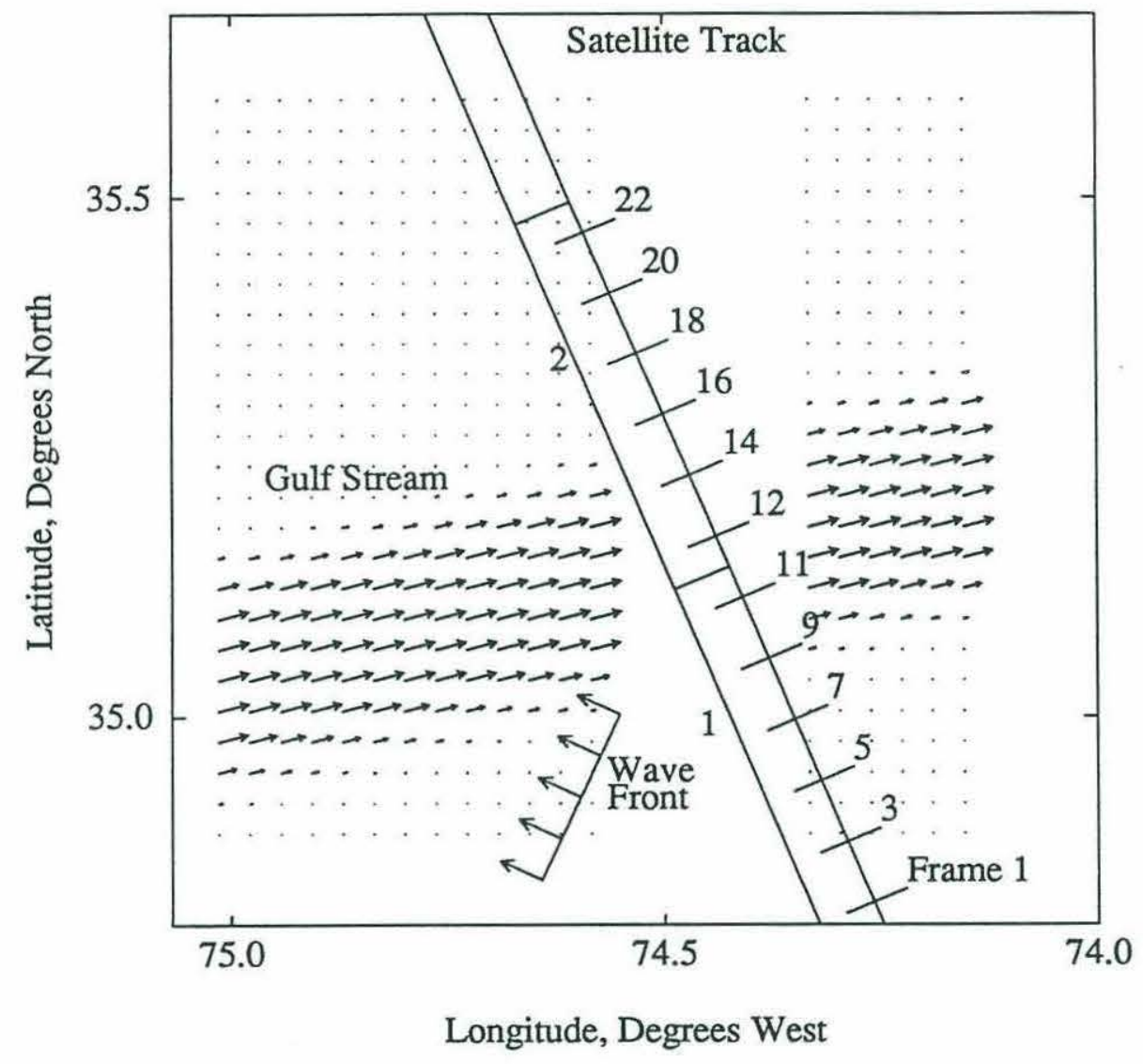

Figure 4-4: Geographical orientation of SEASAT pass 1339 over the Gulf Stream. Numbers at right of track indicate high-resolution SAR image sequence 1 through 22, and numbers at left refer to the two larger $40 \times 40 \mathrm{~km}$ images. 

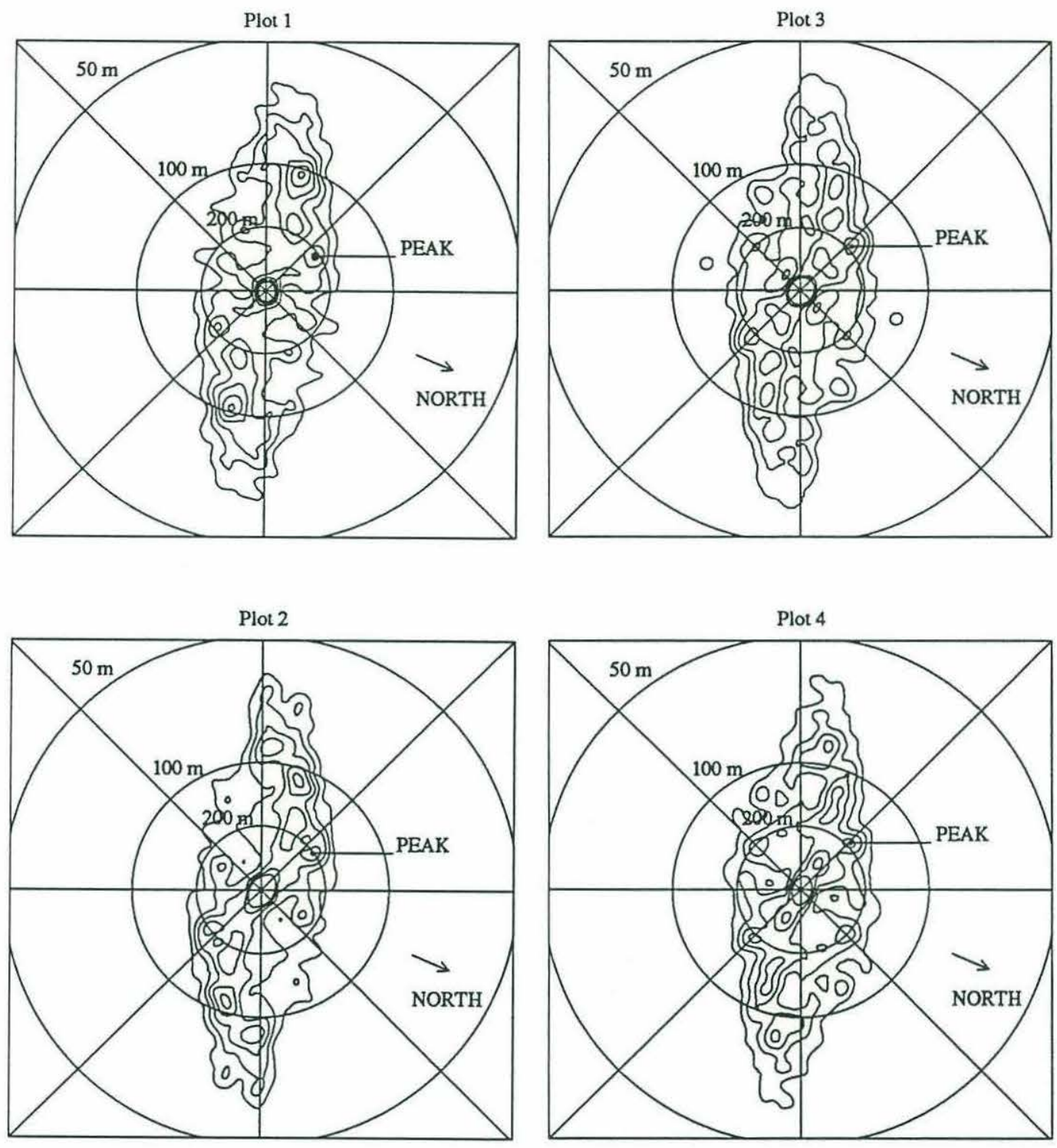

Figure 4-5: SAR wave spectra: images 1 through 4. 

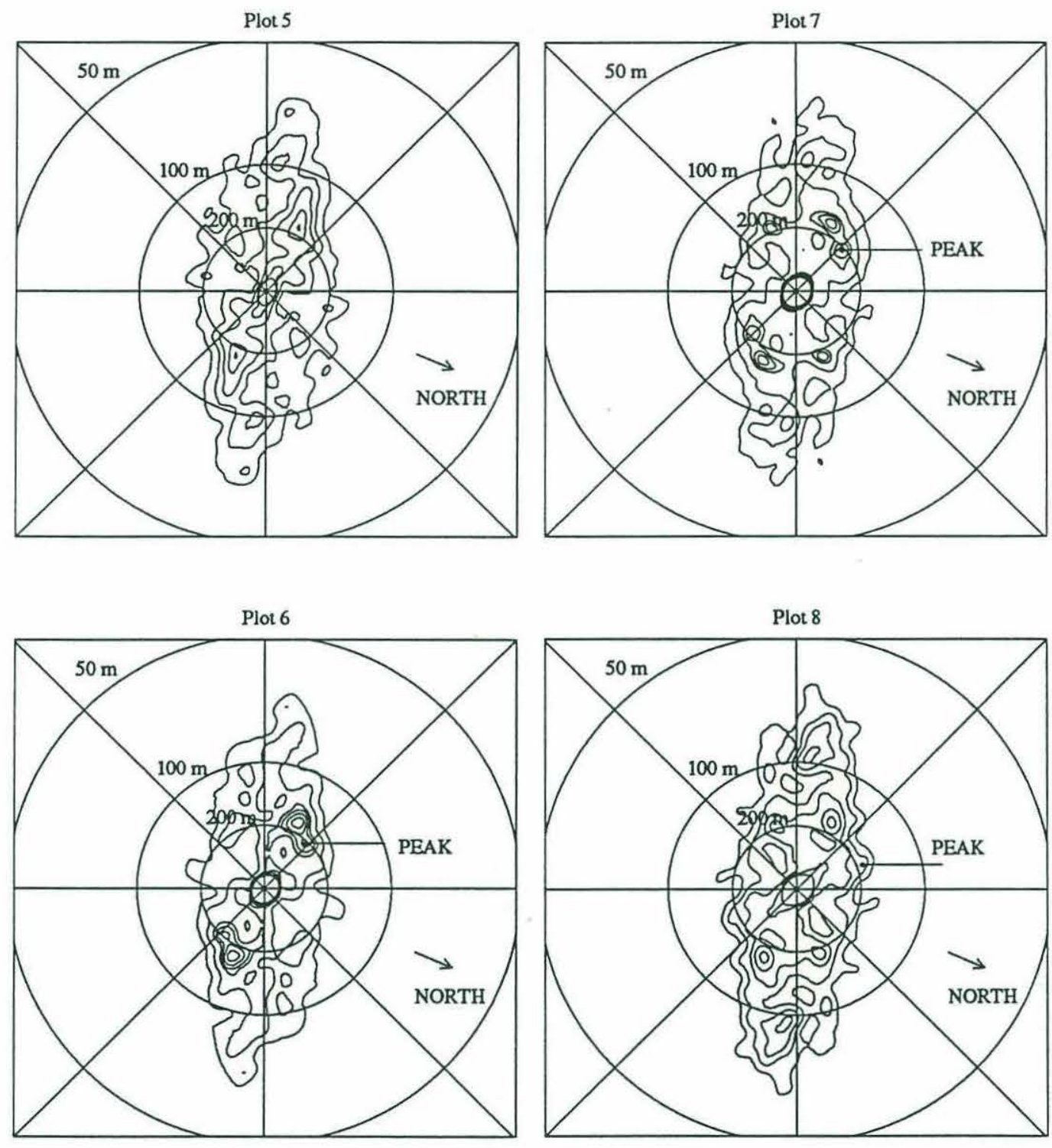

Figure 4-6: SAR wave spectra: images 5 through 8. The Gulf Stream edge is located between images 7 and 8 . Note that the energy peak corresponding to the wave system of interest is not evident in image 5 . 

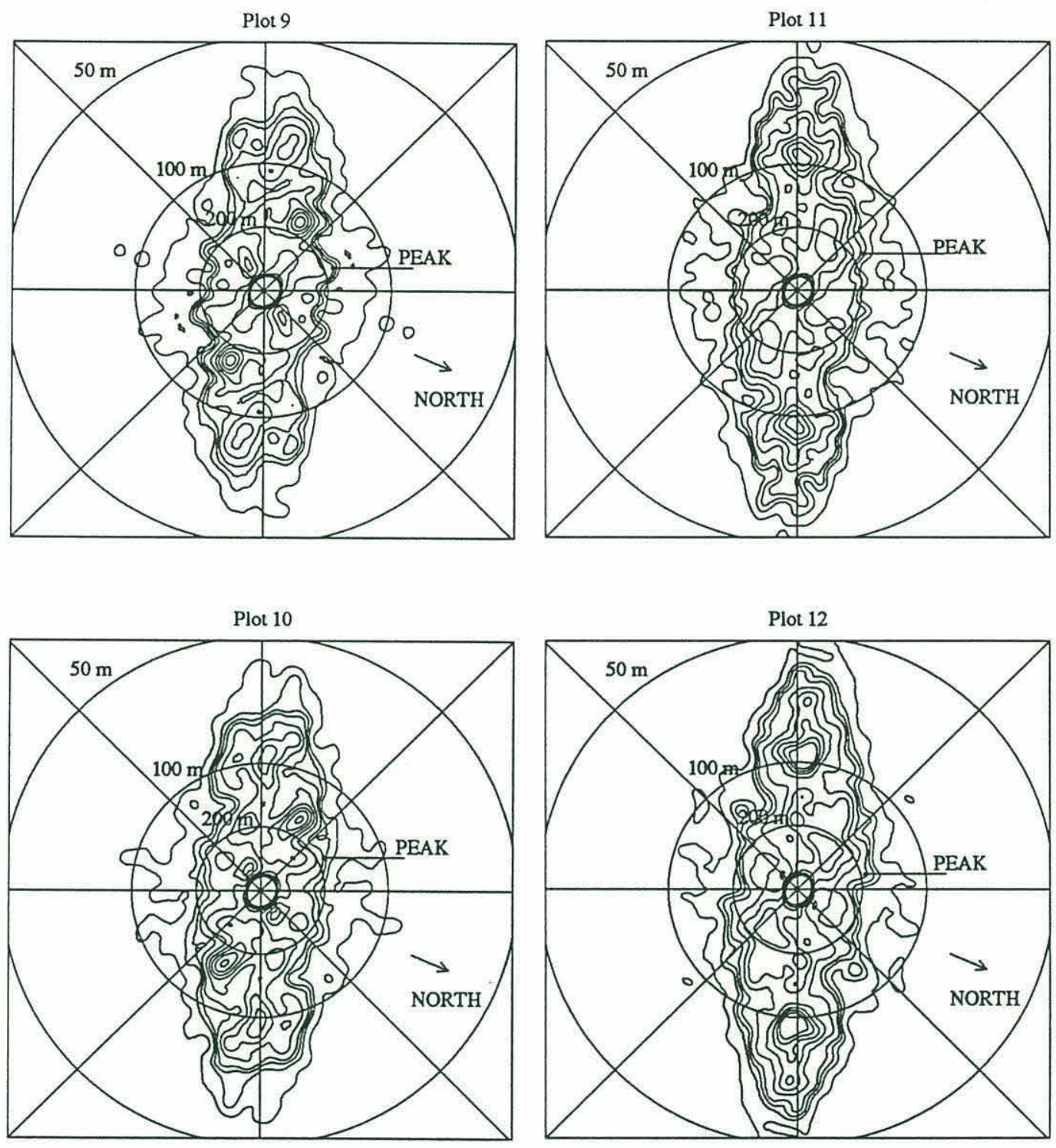

Figure 4-7: SAR wave spectra: images 9 through 12 . Note a $6.7 \mathrm{~km}$ gap occurs between spectra 11 and 12 . 

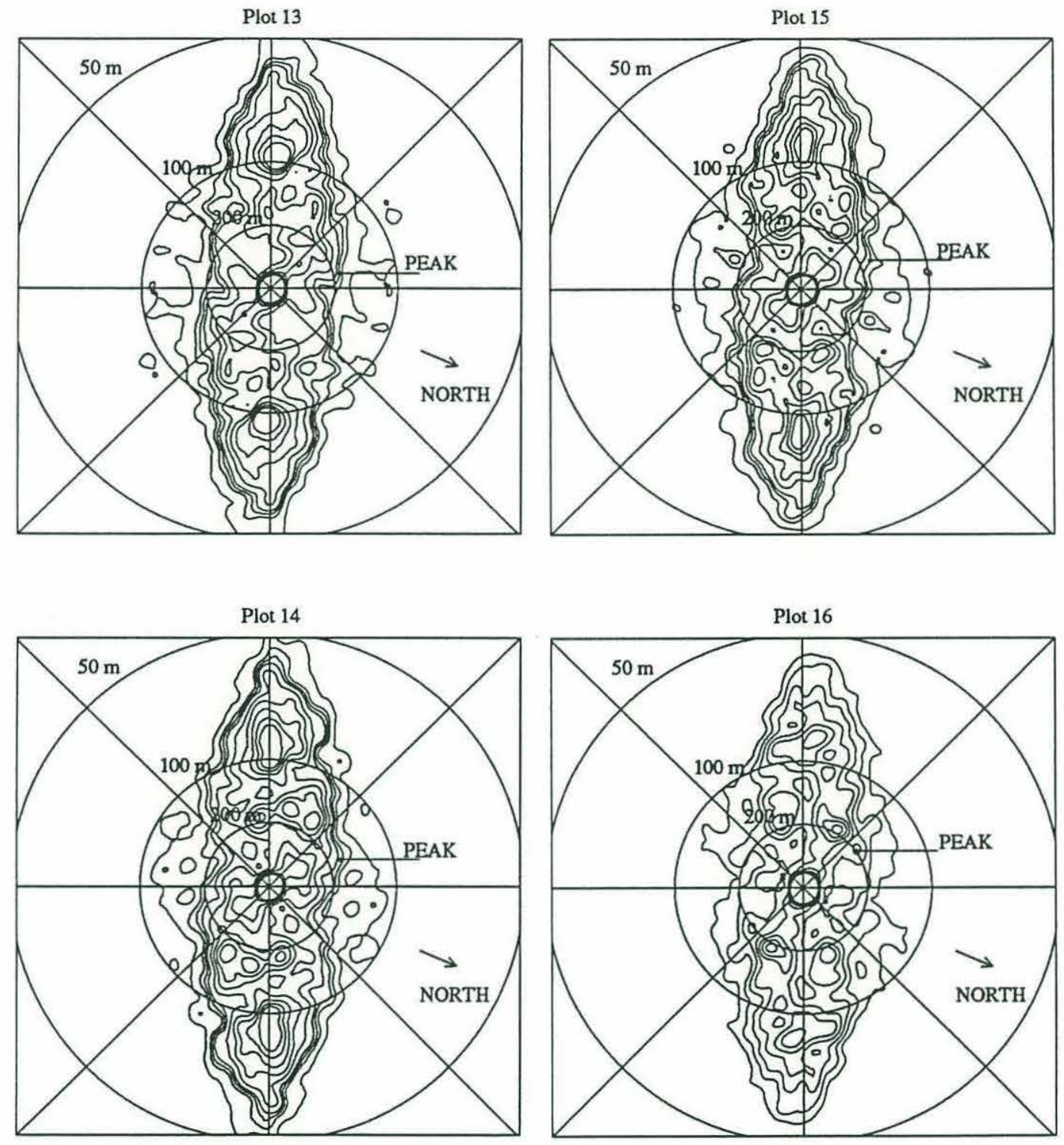

Figure 4-8: SAR wave spectra: images 13 through 16 . The North Wall of the Gulf Stream is located between images 15 and 16 . 

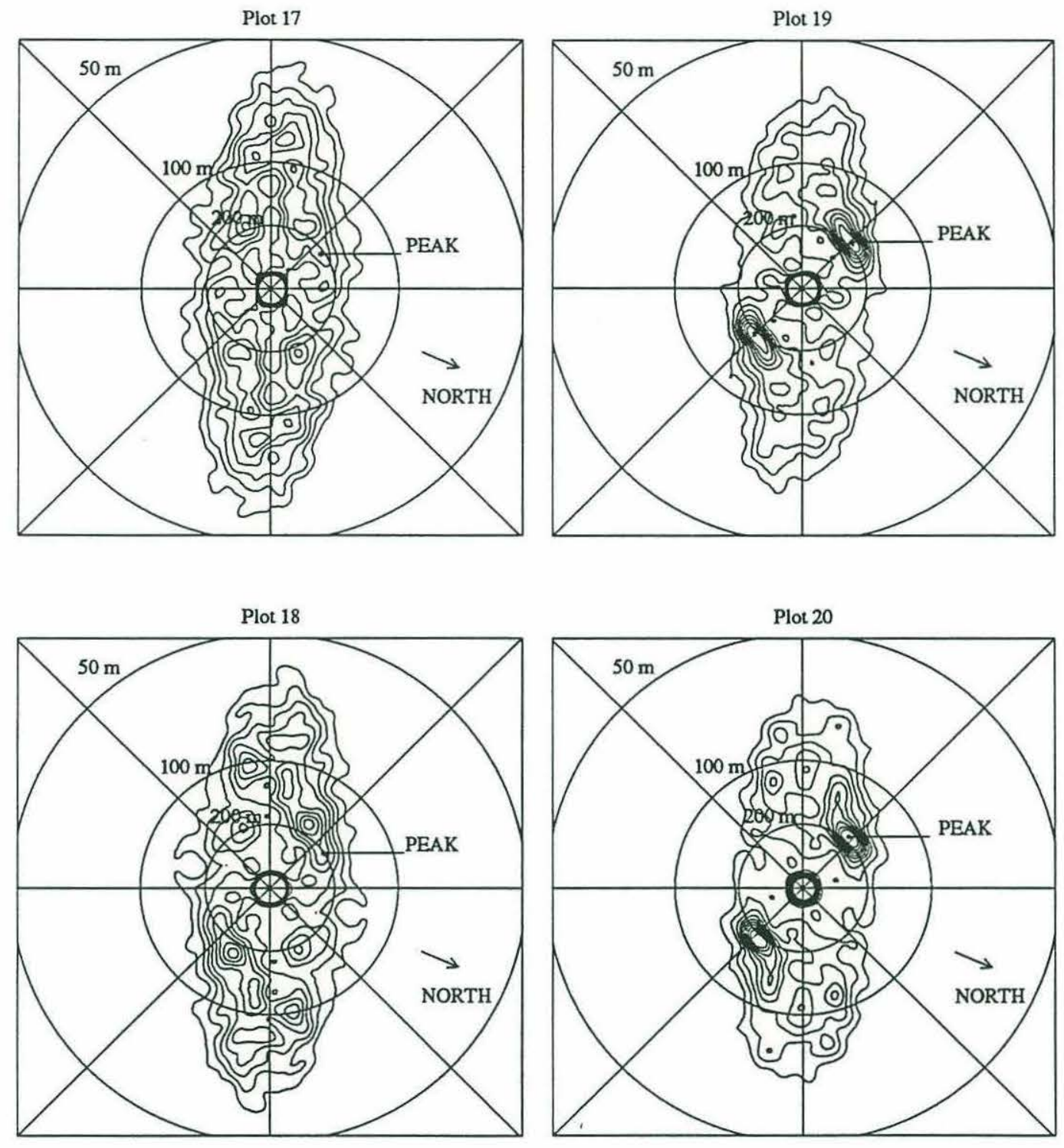

Figure 4-9: SAR wave spectra: images 17 through 20. 

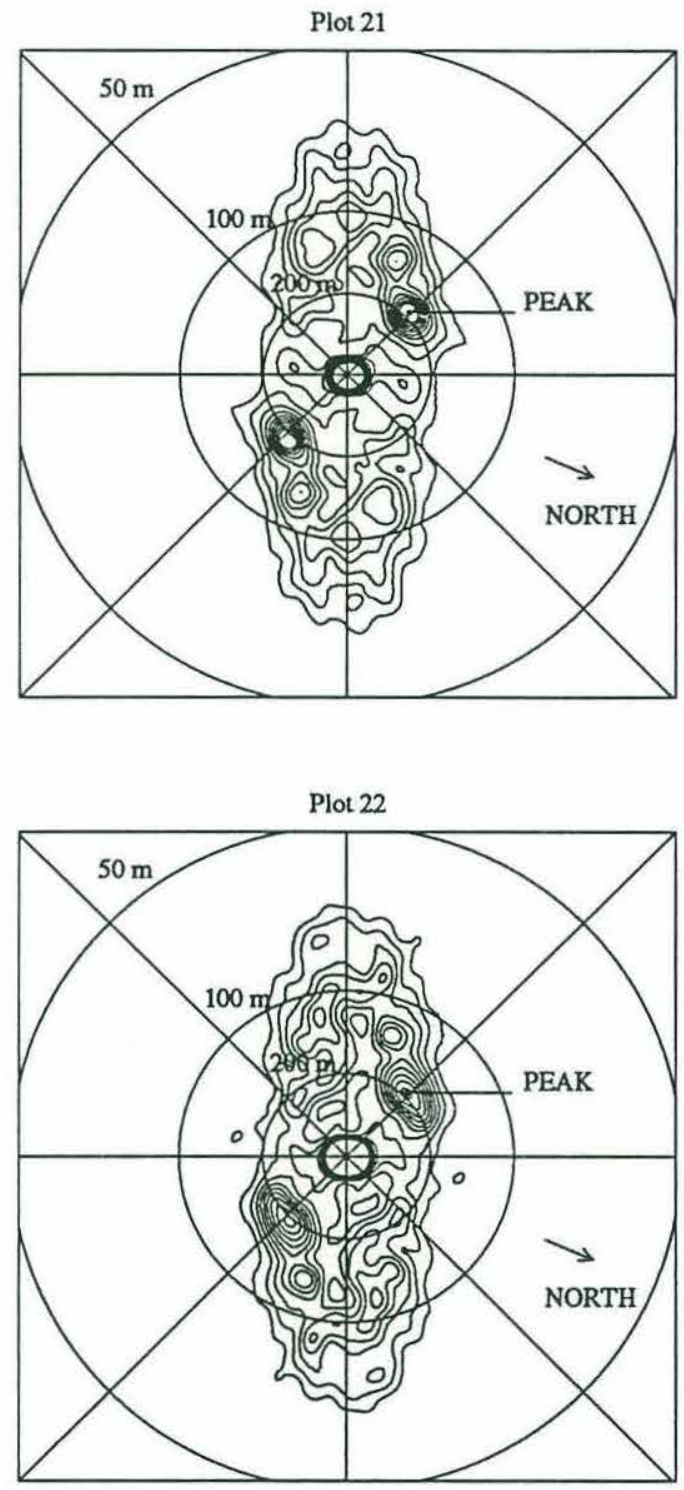

Figure 4-10: SAR wave spectra: images 21 and 22. 

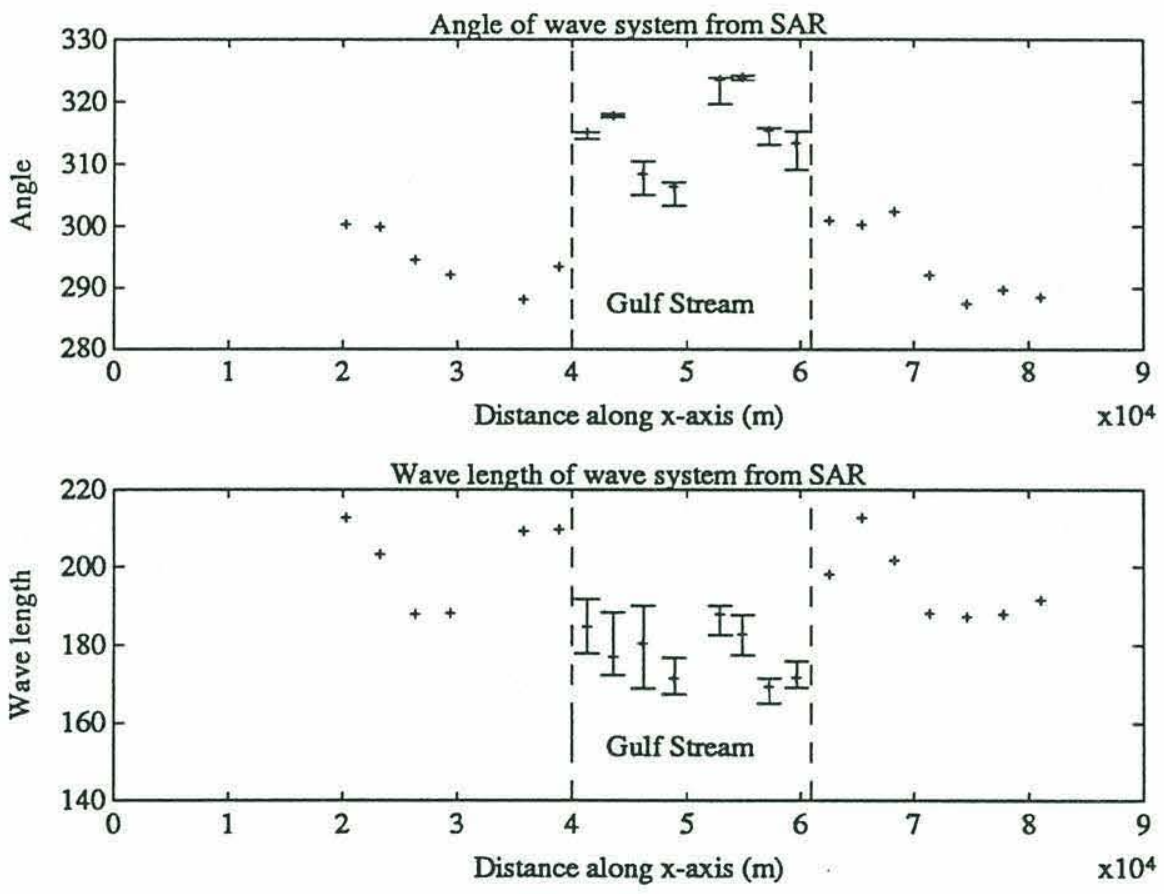

Figure 4-11: Wave length and direction of wave front crossing the Gulf Stream. The error bars represent the range of possible values along the ridges seen in the spectra in the Gulf Stream. The $\mathrm{x}$-axis is oriented along the east-west direction; the waves are propagating toward the coast. 
in the presence of a $2.0 \mathrm{~m} / \mathrm{s}$ current and to $165 \mathrm{~m} / \mathrm{s}$ in the presence of a $2.5 \mathrm{~m} / \mathrm{s}$ current. This is in the range of current velocities often observed in the Gulf Stream (Williams et al. 1974). Within the Gulf Stream, azimuthal smearing results in the energy center appearing as a ridge rather than as a clear peak. The range of possible values along this ridge are shown by the error bars within the Gulf Stream on Figure 4-11. The wave lengths are more variable than the angles, because the smearing in azimuth degrades the wave lengths more than the angles.

Figures 4-12 and 4-13 show the SAR images reduced in resolution. These allow us to visually examine the southern and northern boundaries of the Gulf Stream. The southern boundary seen in Figure 4-12 falls at an angle of about $7^{\circ}$ or $8^{\circ}$ relative to the satellite trajectory. Since the satellite pass was $23^{\circ}$ from North, this indicates that the current was flowing at about $75^{\circ}$ from North at the southern boundary of the Gulf Stream. The northern boundary is very distinct and can be measured to rise at an angle of $7^{\circ}$. This would correspond to a current direction of $60^{\circ}$ at the North Wall of the Gulf Stream. These measurements indicate that the stream is widening at the point at which the satellite passes over.

The data shown in Figure 4-11 imply that the refraction effect is strongest near the northern boundary of the Gulf Stream. This fact would suggest an asymmetric current with a velocity peak shifted towards the North Wall. This might also be a reason why the boundary is more sharply defined in Figure 4-13 than in Figure 4-12.

In order to use the SAR data to estimate the current field at the point at which the satellite passed over the Gulf Stream, a number of possible currents were examined with the refraction model. The width of the Gulf Stream current is estimated to be $33.6 \mathrm{~km}$. This is based on measurements from the $40 \times 40 \mathrm{~km}$ images as well as from the eight spectra between the start and end of the Gulf Stream overpass. The spectra have an average spacing of $3.36 \mathrm{~km}$, and there is another gap of that size between the $40 \times 40 \mathrm{~km}$ images. The satellite pass direction is nearly normal to the Gulf Stream, so a total of ten $3.36 \mathrm{~km}$ spacings results in a current approximately $34 \mathrm{~km}$ wide. The grid spacing used in the numerical model is $51 \times 51$ grid points each $1.68 \mathrm{~km}$ apart (i.e., the model grid spacing is half the size of the spectra spacing). The assumption is also made that 


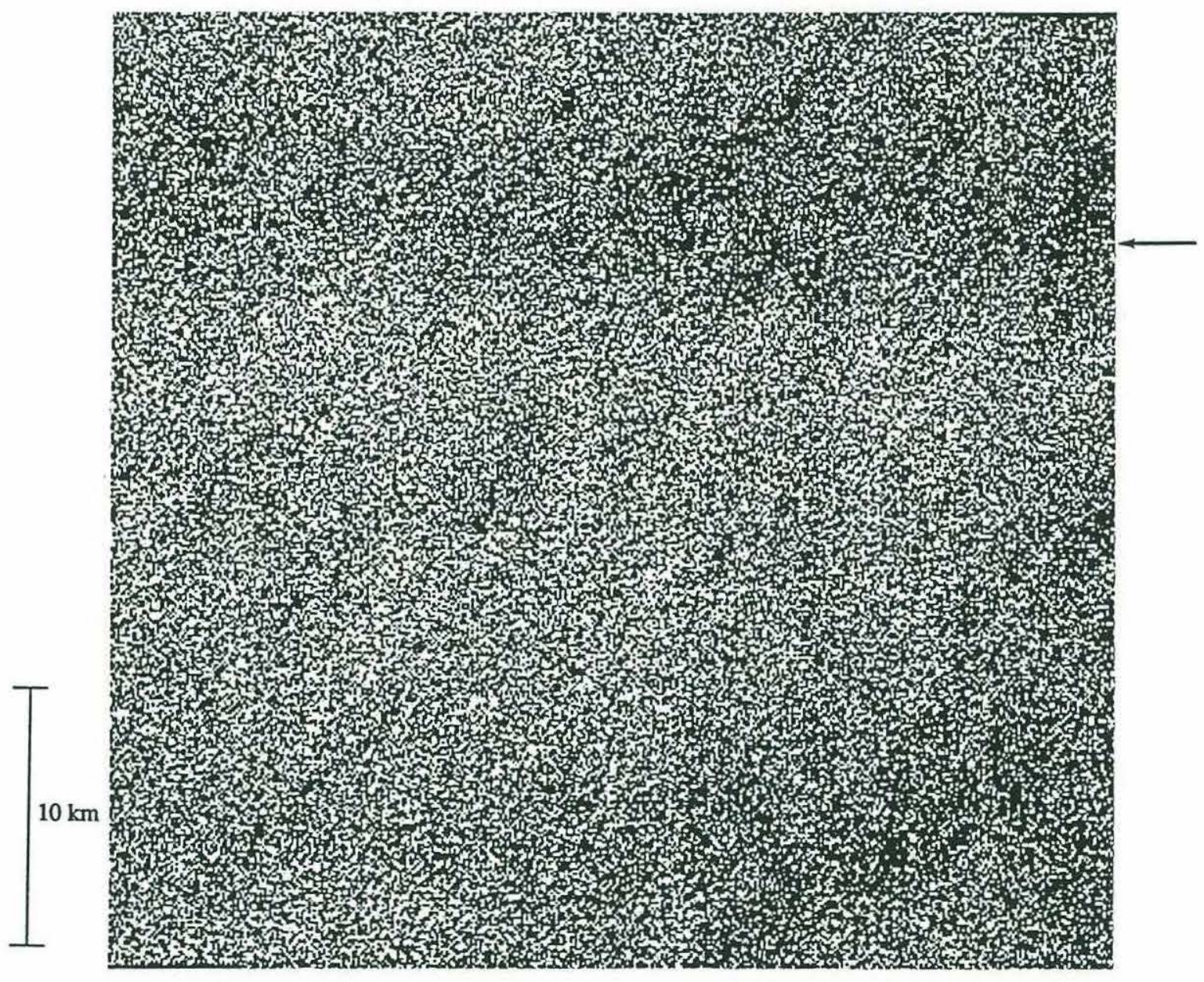

Figure 4-12: First $40 \times 40 \mathrm{~km}$ SAR image showing the location of the southern edge of the Gulf Stream (arrow). 


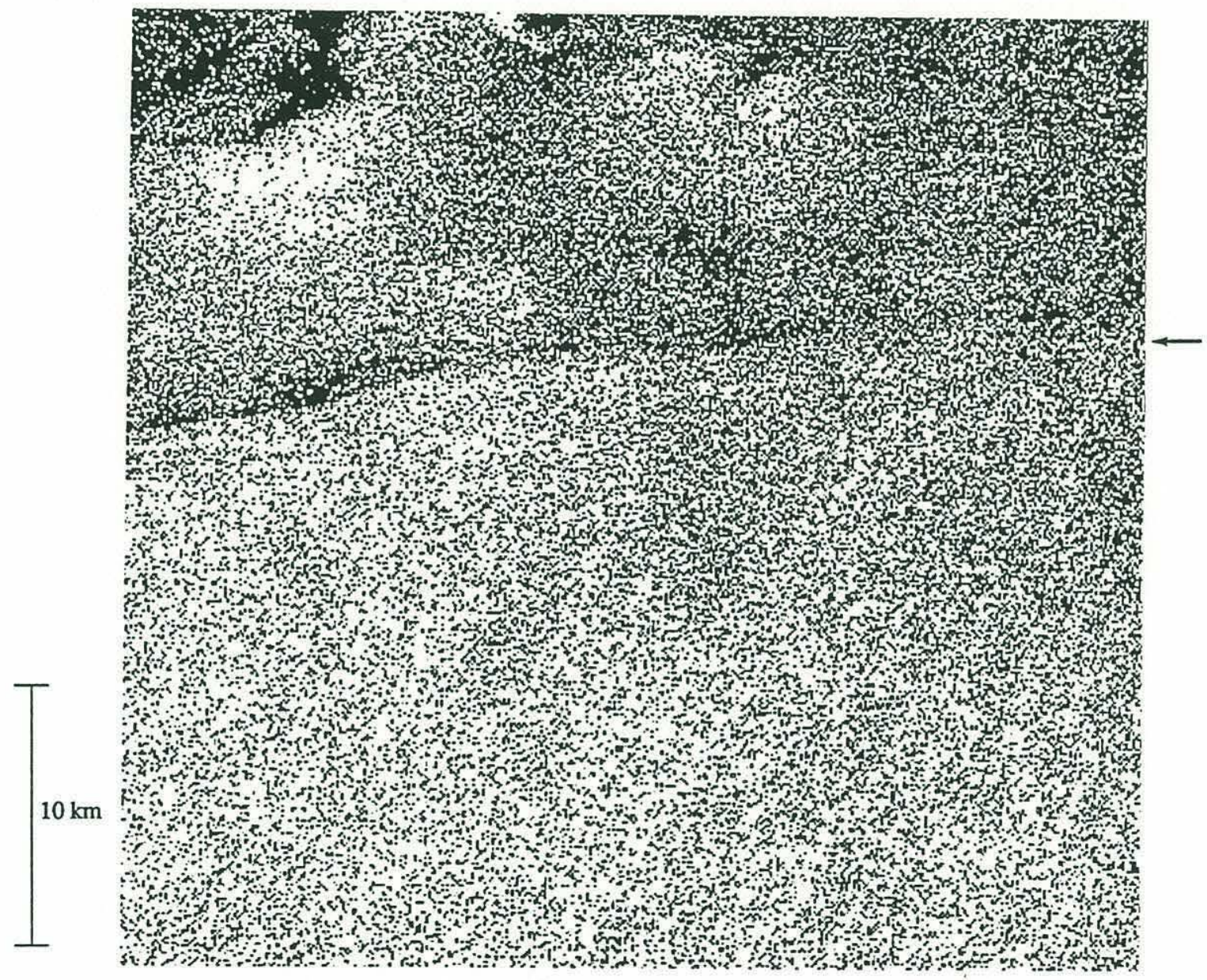

Figure 4-13: Second $40 \times 40 \mathrm{~km}$ SAR image. The northern boundary (North Wall) of the Gulf Stream is clearly visible in the image (arrow). 
the current direction is constant, so eddies and lateral variations within the Gulf Stream are discounted.

Current directions were proposed to vary from $60^{\circ}$ to $75^{\circ}$. The current profiles examined vary with a cosine-squared dependence (symmetic jet), a skewed cosine-squared dependence with the peak closer to the northern boundary of the Gulf Stream (asymmetric jet), and a top hat shape with tapered edges (top hat). Cross-sections of these profiles can be seen in Figure 4-14. Peak current speeds $\left(U_{\max }\right)$ within these profiles of $1.5,2.0,2.25$ and $2.5 \mathrm{~m} / \mathrm{s}$ were examined. Each of these current directions, profiles, and speeds were input into the numerical model for a $200 \mathrm{~m}$ wave with an initial direction of $295^{\circ}$. Note that the average angle of the center of the spectra before the Gulf Stream was $295^{\circ}$, and the average wave length was $200 \mathrm{~m}$ (11.3 second period). Figures 4-15 through 4-17 show the orthogonals and rays being refracted across six model currents.

The wave rays show the propagation of wave energy, so they are compared to the spectra processed from the SAR data. Figures 4-18 and 4-19 show ray angles and wave lengths from the SAR data $(+)$ superimposed on the model output. Both the model and the data are oriented along the $\mathrm{x}$-axis. For each data point, the corresponding model values for angle and wave length are found from simple interpolation. From these two series of wave lengths and angles, two sets of vectors are defined in the direction of the wave ray and with the magnitude of the wave length. The SAR data are compared to the model output by finding the phase angle of the complex correlation coefficient between the two vector series. This technique is described in Kundu (1975). The vectors are defined as:

$$
\omega(t)=u(t)+i v(t)
$$

and are divided into east, $u(t)$, and north, $v(t)$, components. The complex correlation coefficient between the model vector series $\omega_{m}(t)$ and the SAR data vector series $\omega_{d}(t)$ is:

$$
\rho=\frac{\left\langle\omega_{m}^{*}(t) \omega_{d}(t)\right\rangle}{\left\langle\omega_{m}^{*}(t) \omega_{d}(t)\right\rangle^{\frac{1}{2}}\left\langle\omega_{d}^{*}(t) \omega_{m}(t)\right\rangle^{\frac{1}{2}}}
$$

where $\omega^{*}(t)$ is the complex conjugate. The correlation can also be expressed in terms of 
east-north components, i.e.,

$$
\rho=\frac{\left\langle u_{m} u_{d}+v_{m} v_{d}\right\rangle}{\left.\left\langle u_{m}^{2}+v_{m}^{2}\right\rangle^{\frac{1}{2}}<u_{d}^{2}+v_{d}^{2}\right\rangle^{\frac{1}{2}}}+i \frac{\left\langle u_{m} v_{d}-u_{d} v_{m}\right\rangle}{\left\langle u_{m}^{2}+v_{m}^{2}>^{\frac{1}{2}}<u_{d}^{2}+v_{d}^{2}>^{\frac{1}{2}}\right.}
$$

and the phase angle is :

$$
\epsilon_{\text {avg }}=\tan ^{-1} \frac{\left\langle u_{m} v_{d}-u_{d} v_{m}\right\rangle}{\left.<u_{m} u_{d}+v_{m} v_{d}\right\rangle}
$$

Note that $\langle\ldots\rangle$ indicates the average value of the included series. These complex correlations are listed in Tables 4.1, 4.2, and 4.3. All magnitudes of correlation are high because the vectors are all pointing close to the same direction.

To provide another measure of how well the numerical model output fits the SAR data, the wave length and angle are examined individually by calculating residuals. The residual variance in wave length and angle are calculated from the deviation of the model results from the SAR data:

$$
\begin{gathered}
\text { wave length residual }=\frac{1}{N} \sum\left(x_{w l}-m_{w l}\right)^{2} \\
\text { angle residual }=\frac{1}{N} \sum\left(x_{\text {ang }}-m_{\text {ang }}\right)^{2}
\end{gathered}
$$

where $\mathrm{N}$ is the number of data points $x_{w l}$ and $x_{a n g}$ are the SAR measured wave lengths and angles, and $m_{w l}$ and $m_{\text {ang }}$ are the numerical model generated wave lengths and angles.

The complex correlations and residuals are examined together to find the best overall fit between the SAR data and the model output in order to determine the current characteristics which could explain the observed wave refraction.

As can be seen from Tables 4.1, 4.2, and 4.3, the best overall correlation between the numerical refraction model and the SAR data is found when the current is represented by a top hat profile, a velocity of $2.0 \mathrm{~m} / \mathrm{s}$, and a direction $75^{\circ}$. In general, the correlation improves as the profile is changed from a symmetric jet, to an asymmetric jet, to a top hat shape. This indicates that most of the refraction occurs as the wave enters and leaves the Gulf Stream, so the current profile within the Gulf Stream at the location of the satellite pass is close to uniform, and the largest velocity gradients are near the current 
(a)

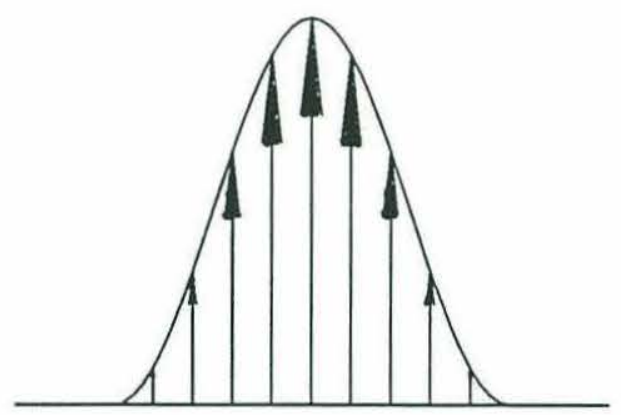

(b)

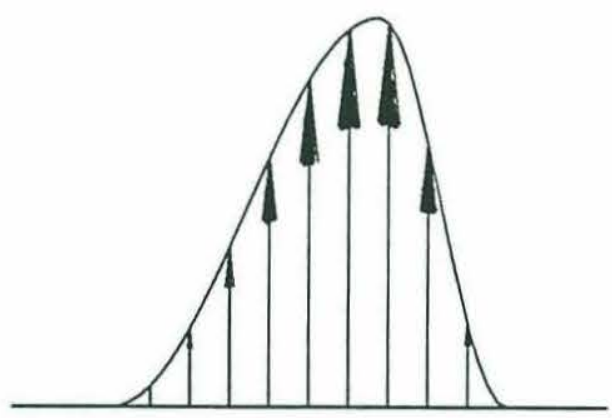

(c)

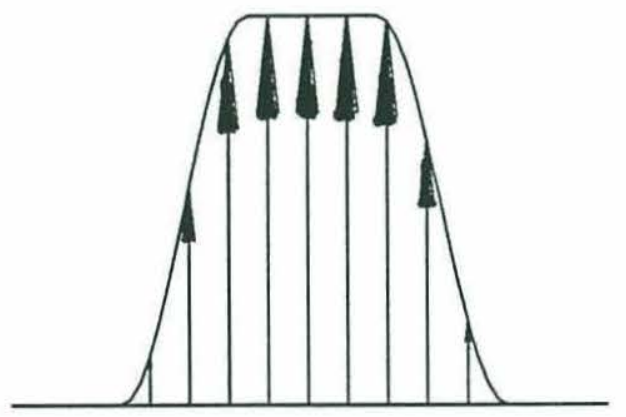

Figure 4-14: Model current profiles: (a) Symmetric jet. (b) Asymmetric jet . (c) Top hat. 
(a)

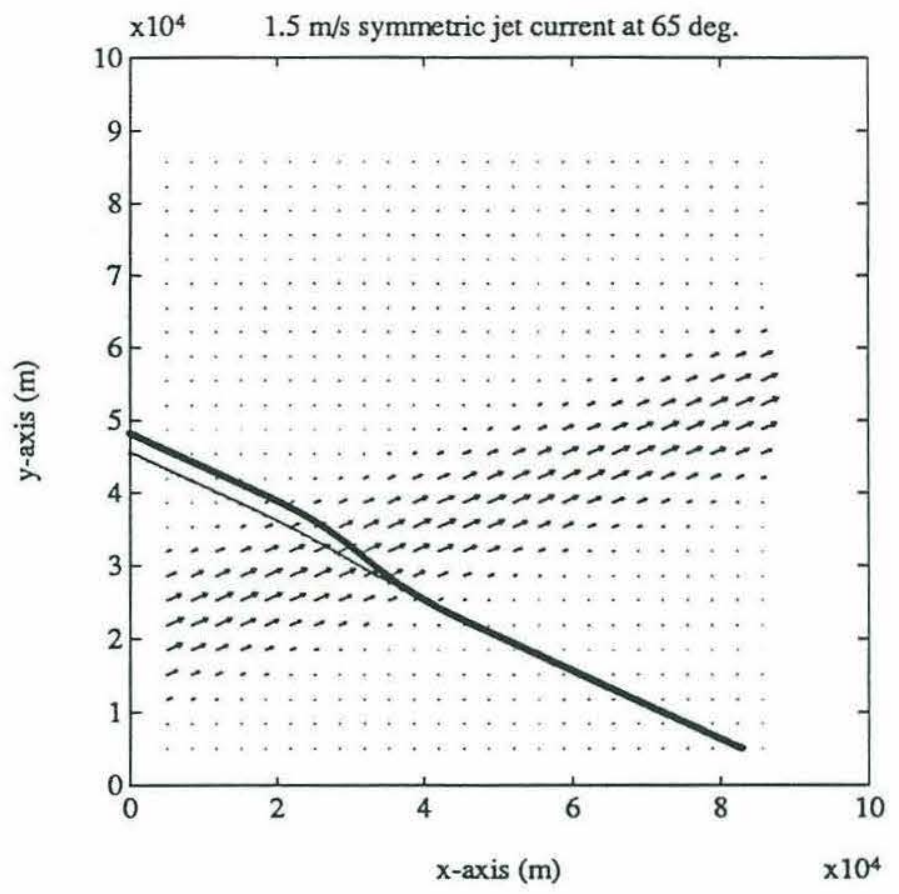

(b)

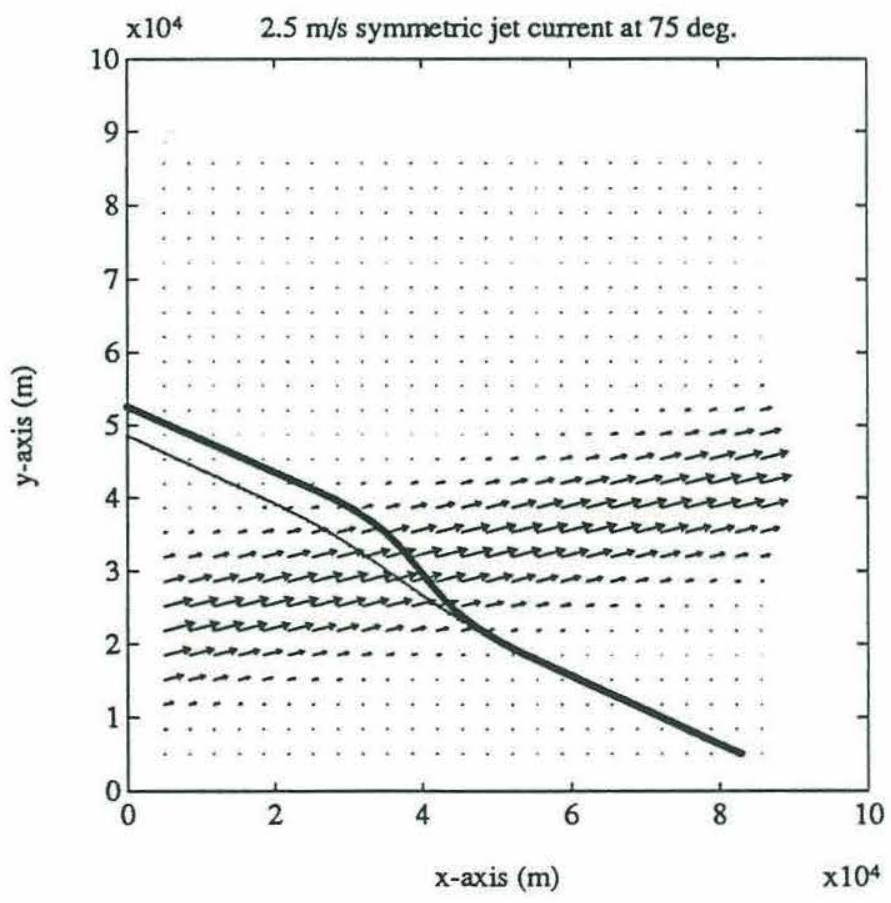

Figure 4-15: Refraction of wave rays and orthogonals across symmetric jet current profiles. (a) $U_{\max }$ is $1.5 \mathrm{~m} / \mathrm{s}$ at $65^{\circ}$. (b) $U_{\max }$ is $2.5 \mathrm{~m} / \mathrm{s}$ at $75^{\circ}$. Note that a heavy line represents the ray path and a thin line the orthogonal path. 
(a)

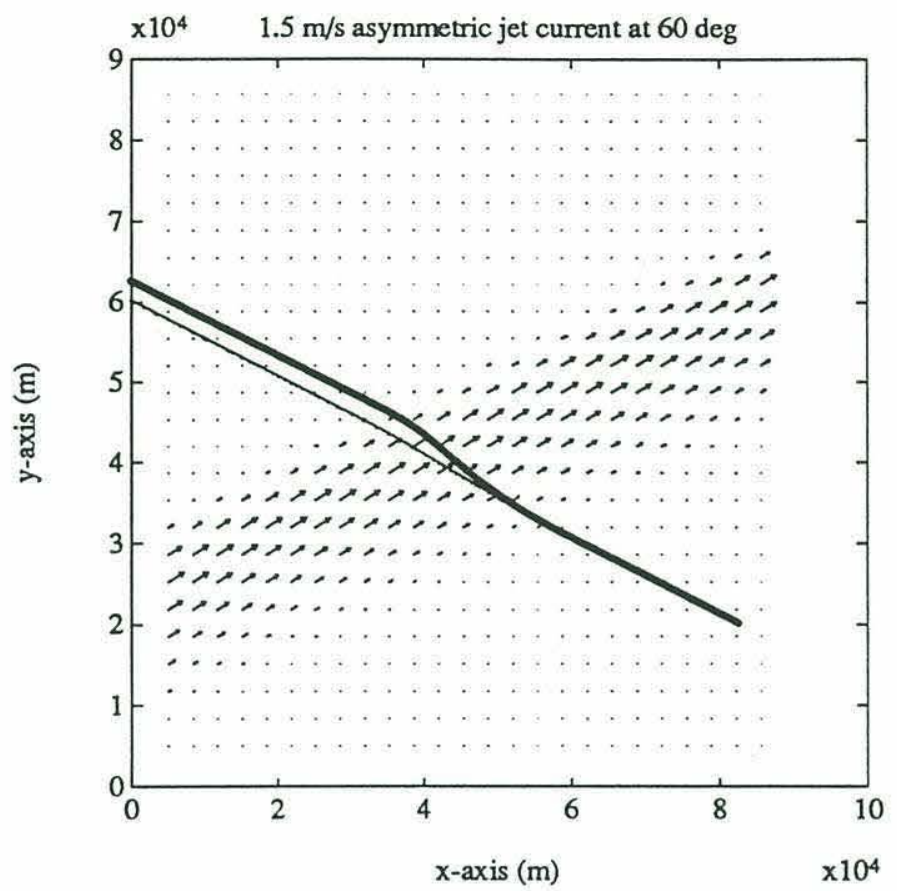

(b)

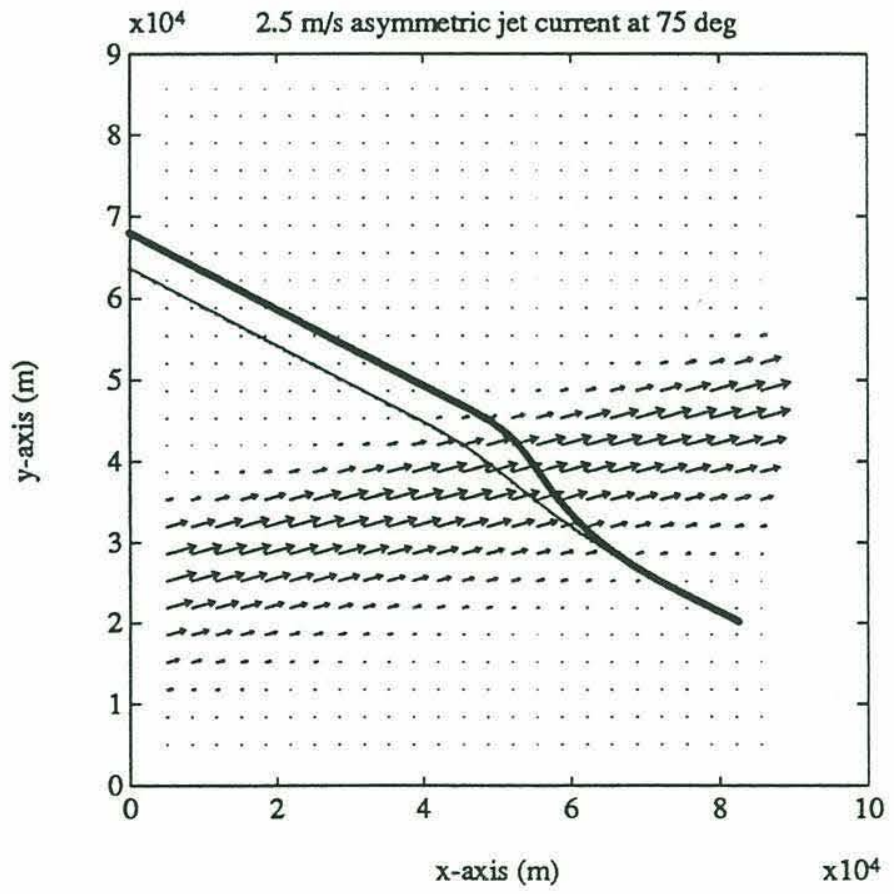

Figure 4-16: Refraction of wave rays and orthogonals across asymmetric jet current profiles. (a) $U_{\max }$ is $1.5 \mathrm{~m} / \mathrm{s}$ at $60^{\circ}$. (b) $U_{\max }$ is $2.5 \mathrm{~m} / \mathrm{s}$ at $75^{\circ}$. Note that a heavy line represents the ray path and a thin line the orthogonal path. 
(a)

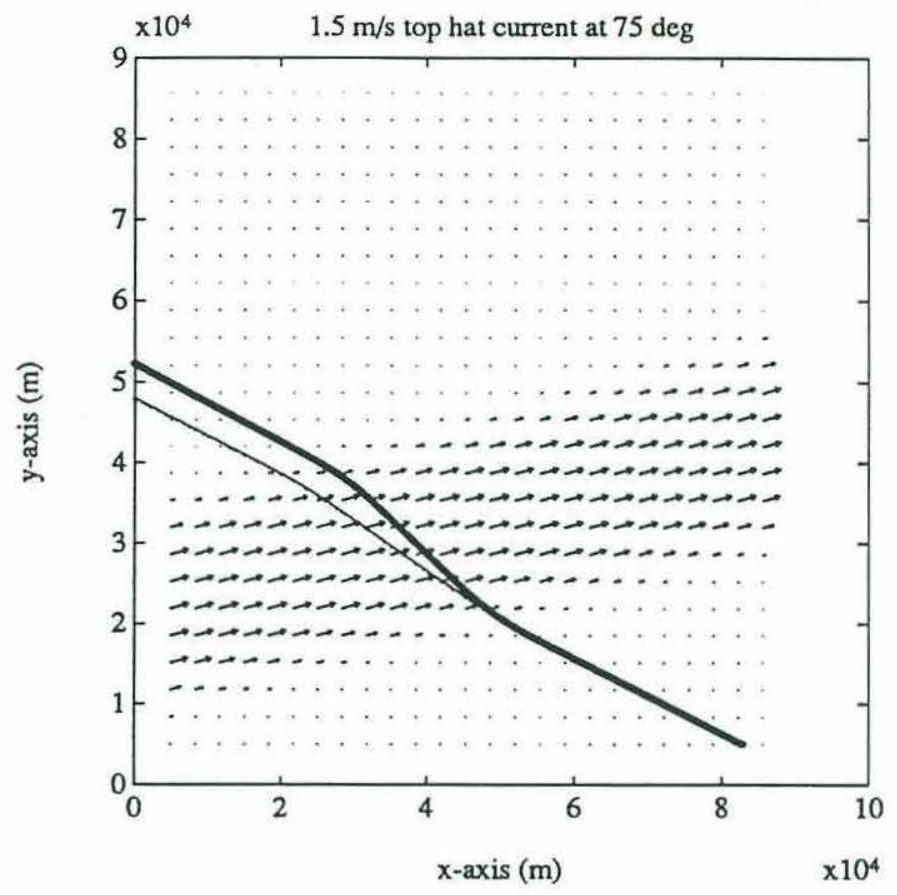

(b)

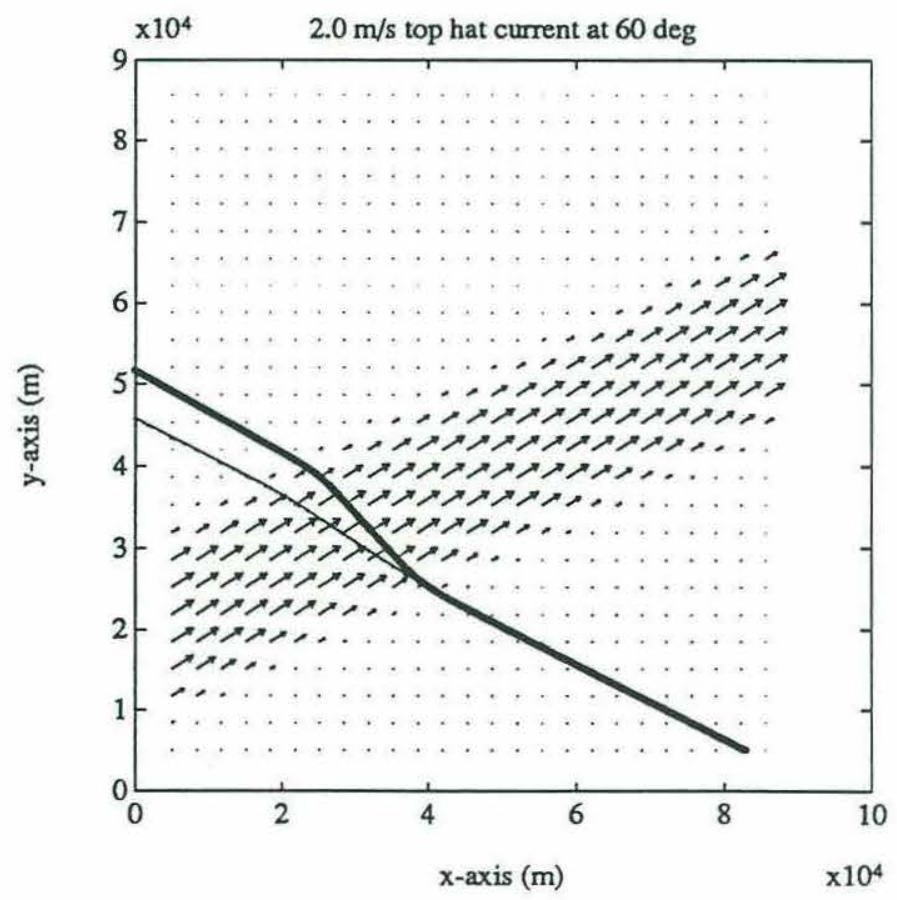

Figure 4-17: Refraction of wave rays and orthogonals across top hat current profiles. (a) $U_{\max }$ is $1.5 \mathrm{~m} / \mathrm{s}$ at $75^{\circ}$. (b) $U_{\max }$ is $2.0 \mathrm{~m} / \mathrm{s}$ at $60^{\circ}$. Note that a heavy line represents the ray path and a thin line the orthogonal path. 
(a)
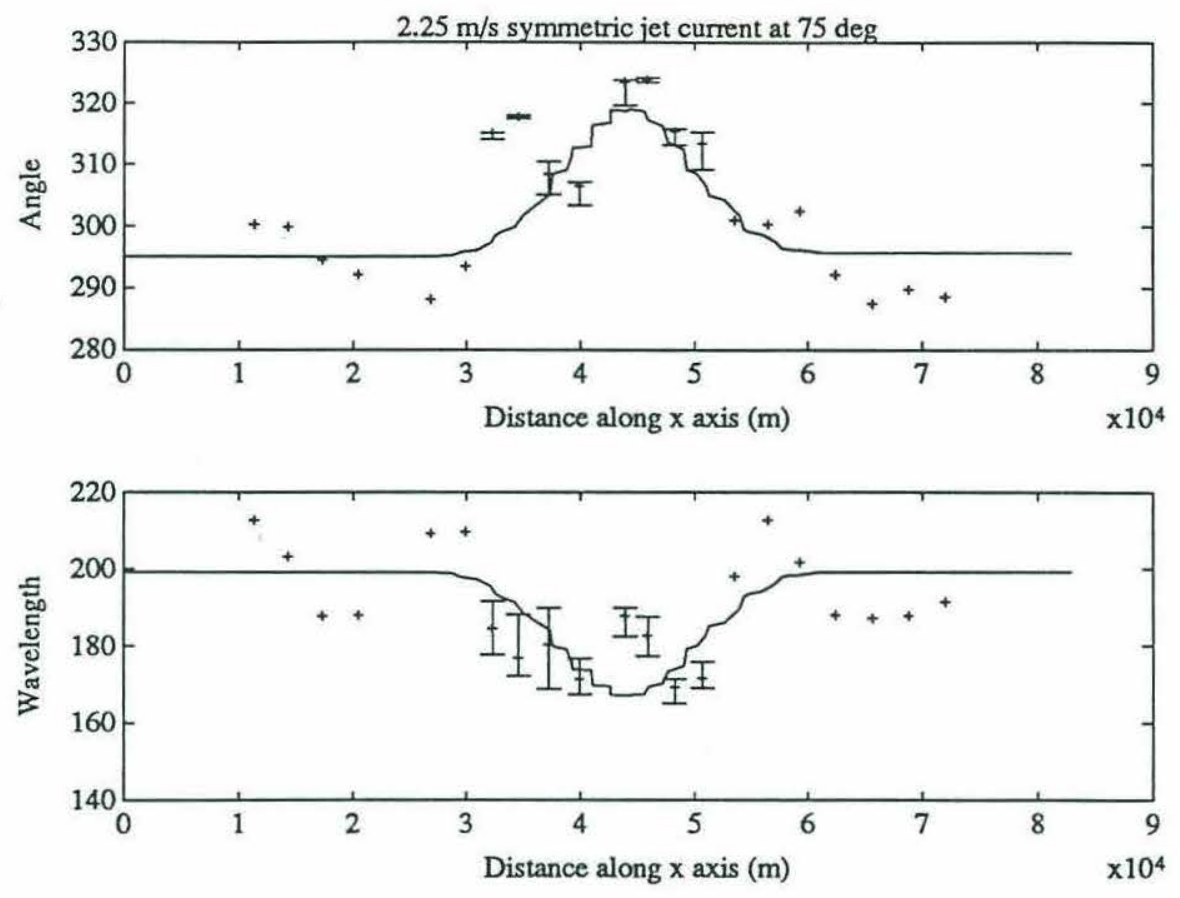

(b)
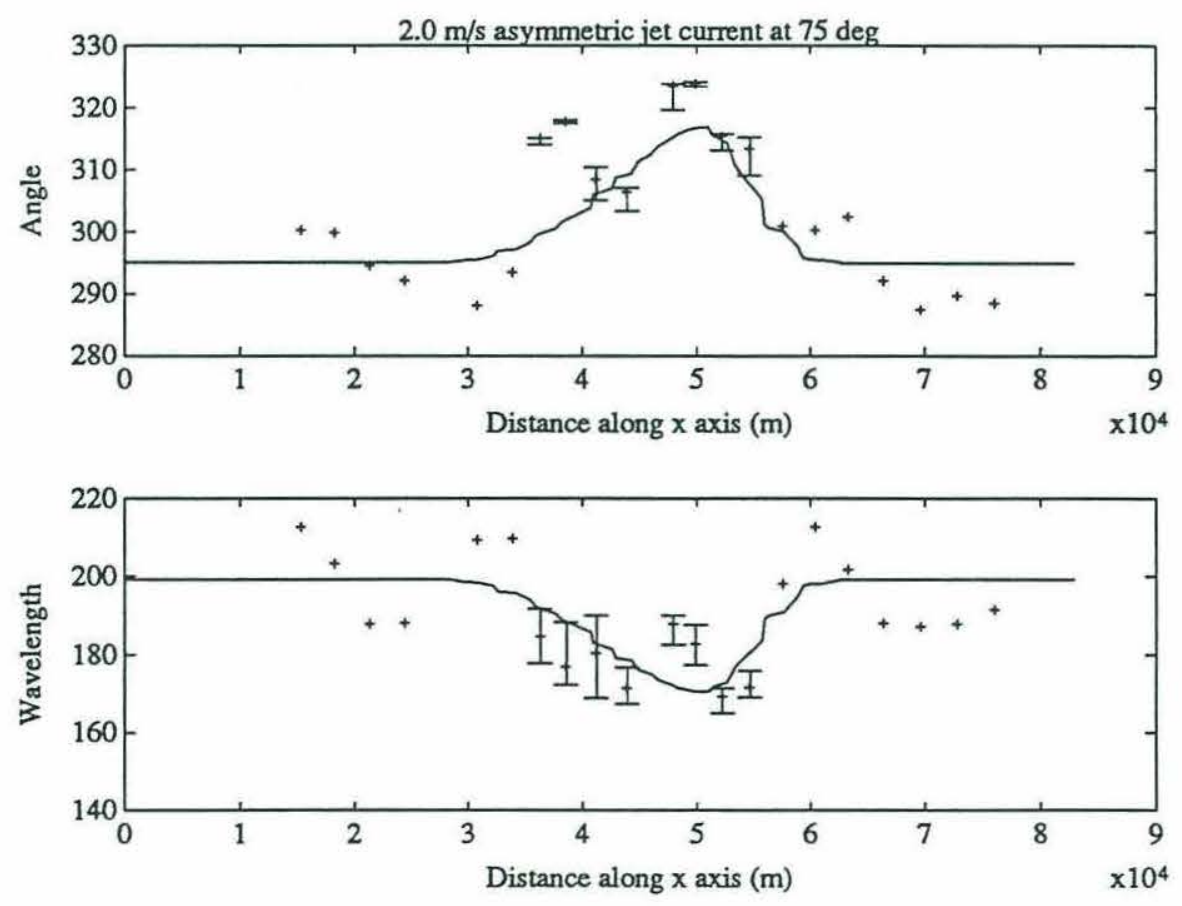

Figure 4-18: (a) Symmetric jet profile. (b) Asymmetric jet profile. SAR data (+) superimposed on model output; the waves are propagating toward the coast. The $\mathrm{x}$-axis corresponds to the east-west direction. 
(a)
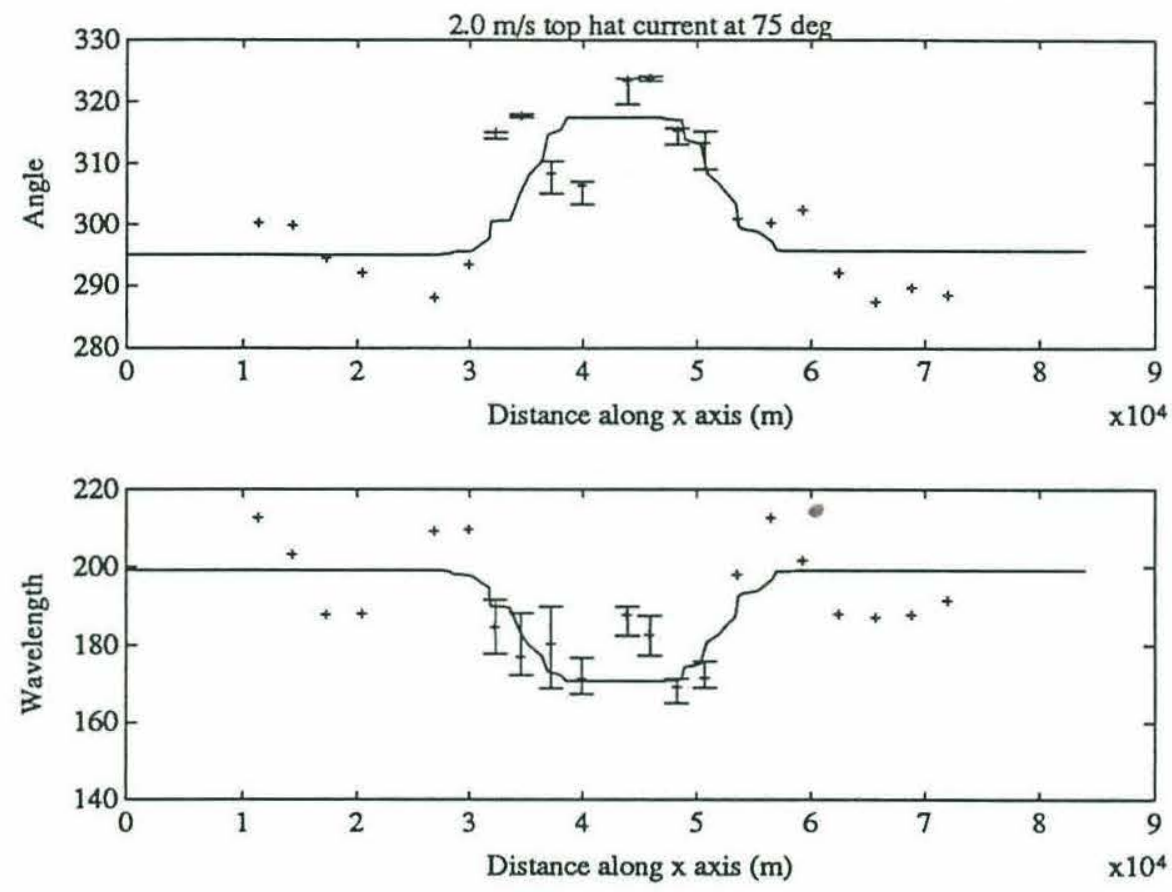

(b)
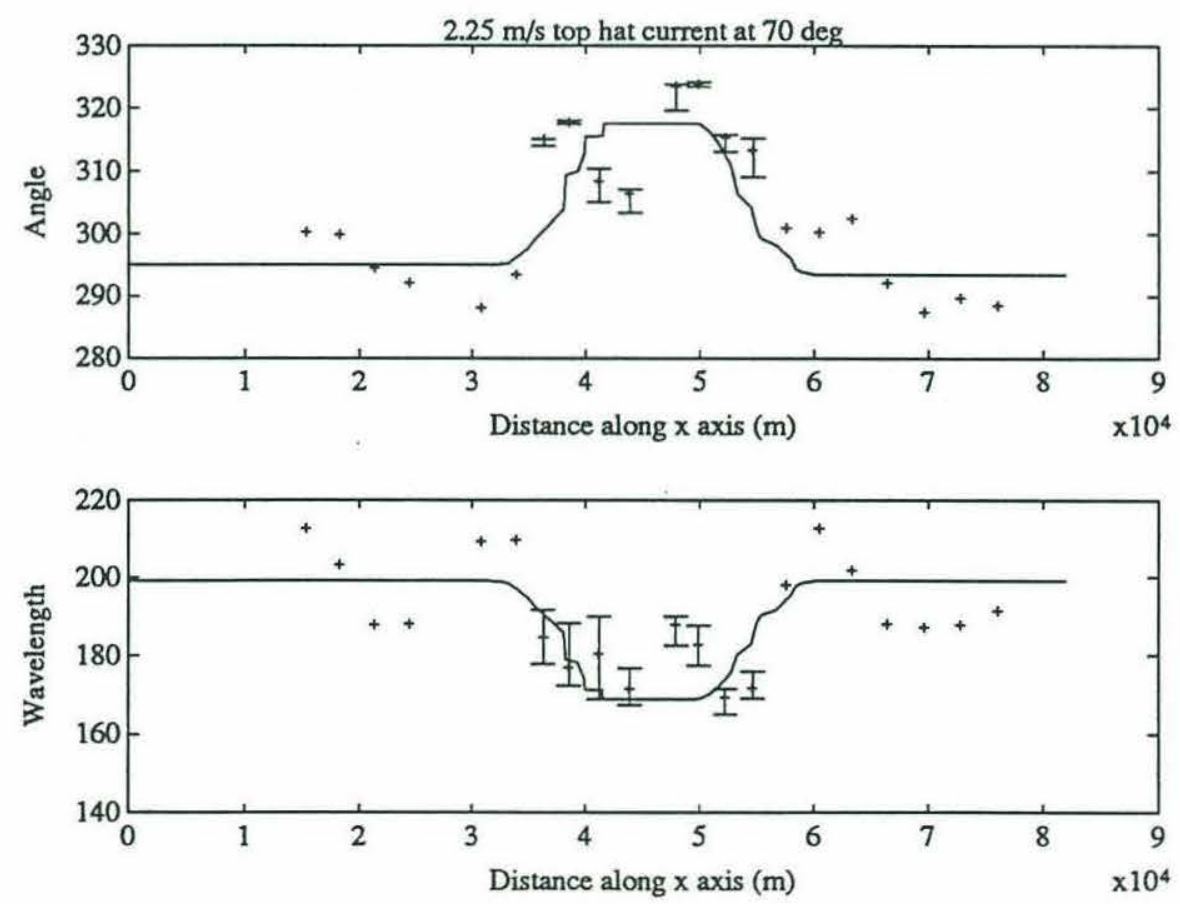

Figure 4-19: (a) Top hat profile with $2 \mathrm{~m} / \mathrm{s}$ current. (b) Top hat profile with 2.25 $\mathrm{m} / \mathrm{s}$ current. SAR data $(+)$ superimposed on model output; the waves are propagating toward the coast. The $\mathrm{x}$-axis corresponds to the east-west direction. 


\begin{tabular}{|l|l|l|l|l|l|}
\hline$U_{\max }$ & $\begin{array}{l}\text { Current } \\
\text { Direction }\end{array}$ & $\begin{array}{l}\text { Magnitude of } \\
\text { Correlation }\end{array}$ & $\begin{array}{l}\text { Phase } \\
\text { Angle }\end{array}$ & $\begin{array}{l}\text { Angle } \\
\text { Residual } \text { deg }^{2}\end{array}$ & $\begin{array}{l}\text { Wave Length } \\
\text { Residual } m^{2}\end{array}$ \\
\hline \hline 1.5 & $60^{\circ}$ & .9908 & $4.0180^{\circ}$ & 89.8 & 136.3 \\
1.5 & $65^{\circ}$ & .9916 & $3.6014^{\circ}$ & 82.1 & 125.1 \\
1.5 & $70^{\circ}$ & .9923 & $2.9953^{\circ}$ & 74.1 & 118.2 \\
1.5 & $75^{\circ}$ & .9932 & $2.7280^{\circ}$ & 67.4 & 110.9 \\
2.0 & $60^{\circ}$ & .9922 & $3.0911^{\circ}$ & 74.6 & 127.1 \\
2.0 & $65^{\circ}$ & .9926 & $2.3074^{\circ}$ & 67.8 & 121.8 \\
2.0 & $70^{\circ}$ & .9937 & $1.8731^{\circ}$ & 60.7 & 111.7 \\
2.0 & $75^{\circ}$ & .9952 & $1.7376^{\circ}$ & 50.5 & 113.6 \\
2.25 & $60^{\circ}$ & .9928 & $3.0420^{\circ}$ & 70.1 & 128.8 \\
2.25 & $65^{\circ}$ & .9932 & $2.1865^{\circ}$ & 63.1 & 127.0 \\
2.25 & $70^{\circ}$ & .9943 & $1.7043^{\circ}$ & 56.7 & 114.6 \\
$\mathbf{2 . 2 5}$ & $\mathbf{7 5}^{\circ}$ & .9950 & $1.1597^{\circ}$ & $\mathbf{5 0 . 7}$ & 123.8 \\
2.5 & $60^{\circ}$ & .9919 & $2.3578^{\circ}$ & 73.0 & 132.6 \\
2.5 & $65^{\circ}$ & .9928 & $1.4241^{\circ}$ & 63.0 & 133.4 \\
2.5 & $70^{\circ}$ & .9942 & $1.3091^{\circ}$ & 56.4 & 124.8 \\
2.5 & $75^{\circ}$ & .9956 & $1.4134^{\circ}$ & 48.7 & 127.4 \\
\hline
\end{tabular}

Table 4.1: Correlations of SAR data vs numerical refraction model for symmetric jet current profile.

\begin{tabular}{|l|l|l|l|l|l|}
\hline$U_{\max }$ & $\begin{array}{l}\text { Current } \\
\text { Direction }\end{array}$ & $\begin{array}{l}\text { Magnitude of } \\
\text { Correlation }\end{array}$ & $\begin{array}{l}\text { Phase } \\
\text { Angle }\end{array}$ & $\begin{array}{l}\text { Angle } \\
\text { Residual } \text { deg }^{2}\end{array}$ & $\begin{array}{l}\text { Wave Length } \\
\text { Residual } m^{2}\end{array}$ \\
\hline \hline 1.5 & $60^{\circ}$ & .9908 & $4.0341^{\circ}$ & 89.6 & 134.3 \\
1.5 & $65^{\circ}$ & .9918 & $3.4259^{\circ}$ & 79.7 & 121.3 \\
1.5 & $70^{\circ}$ & .9928 & $3.0297^{\circ}$ & 71.5 & 108.9 \\
1.5 & $75^{\circ}$ & .9933 & $2.3724^{\circ}$ & 64.3 & 110.8 \\
2.0 & $60^{\circ}$ & .9927 & $3.0574^{\circ}$ & 70.4 & 123.2 \\
2.0 & $65^{\circ}$ & .9928 & $2.0540^{\circ}$ & 65.7 & 119.2 \\
2.0 & $70^{\circ}$ & .9939 & $1.5348^{\circ}$ & 57.8 & 112.9 \\
2.0 & $75^{\circ}$ & .9958 & $1.5629^{\circ}$ & 46.8 & 106.1 \\
2.25 & $60^{\circ}$ & .9936 & $3.1710^{\circ}$ & 66.0 & 122.1 \\
2.25 & $65^{\circ}$ & .9942 & $2.3687^{\circ}$ & 58.5 & 117.2 \\
2.25 & $70^{\circ}$ & .9953 & $1.7400^{\circ}$ & 50.2 & 110.8 \\
2.25 & $75^{\circ}$ & .9955 & $0.6293^{\circ}$ & 46.7 & 118.3 \\
2.5 & $60^{\circ}$ & .9929 & $2.7747^{\circ}$ & 68.2 & 126.0 \\
2.5 & $65^{\circ}$ & .9938 & $1.4798^{\circ}$ & 58.0 & 120.0 \\
$\mathbf{2 . 5}$ & $\mathbf{7 0}^{\circ}$ & .9951 & $1.6270^{\circ}$ & $\mathbf{5 1 . 2}$ & $\mathbf{1 2 2 . 5}$ \\
2.5 & $75^{\circ}$ & .9962 & $2.4065^{\circ}$ & 48.4 & 122.0 \\
\hline
\end{tabular}

Table 4.2: Correlations of SAR data vs numerical refraction model for asymmetric jet current profile. 


\begin{tabular}{|l|l|l|l|l|l|}
\hline$U_{\max }$ & $\begin{array}{l}\text { Current } \\
\text { Direction }\end{array}$ & $\begin{array}{l}\text { Magnitude of } \\
\text { Correlation }\end{array}$ & $\begin{array}{l}\text { Phase } \\
\text { Angle }\end{array}$ & $\begin{array}{l}\text { Angle } \\
\text { Residual } \mathrm{deg}^{2}\end{array}$ & $\begin{array}{l}\text { Wave Length } \\
\text { Residual } \mathrm{m}^{2}\end{array}$ \\
\hline \hline 1.5 & $60^{\circ}$ & .9921 & $3.1317^{\circ}$ & 75.7 & 112.0 \\
1.5 & $65^{\circ}$ & .9940 & $2.4323^{\circ}$ & 61.7 & 95.5 \\
1.5 & $70^{\circ}$ & .9941 & $2.1287^{\circ}$ & 58.2 & 92.8 \\
1.5 & $75^{\circ}$ & .9953 & $1.0883^{\circ}$ & 49.3 & 96.0 \\
2.0 & $60^{\circ}$ & .9930 & $1.7350^{\circ}$ & 64.3 & 108.3 \\
2.0 & $65^{\circ}$ & .9945 & $0.9586^{\circ}$ & 54.8 & 99.7 \\
2.0 & $70^{\circ}$ & .9936 & $0.5190^{\circ}$ & 48.4 & 94.1 \\
2.0 & $7^{\circ}$ & .9963 & $0.1357^{\circ}$ & 45.1 & 98.9 \\
2.25 & $60^{\circ}$ & .9937 & $2.0353^{\circ}$ & 61.7 & 110.2 \\
2.25 & $65^{\circ}$ & .9926 & $0.0347^{\circ}$ & 66.2 & 114.0 \\
2.25 & $70^{\circ}$ & .9965 & $1.3584^{\circ}$ & 46.4 & 106.8 \\
2.25 & $75^{\circ}$ & .9972 & $0.5551^{\circ}$ & 41.5 & 111.2 \\
2.5 & $60^{\circ}$ & .9929 & $2.5981^{\circ}$ & 70.0 & 120.3 \\
2.5 & $65^{\circ}$ & .9943 & $2.5297^{\circ}$ & 63.4 & 119.1 \\
2.5 & $70^{\circ}$ & .9948 & $1.8436^{\circ}$ & 60.6 & 136.0 \\
2.5 & $75^{\circ}$ & .9955 & $-.1881^{\circ}$ & 54.5 & 126.2 \\
\hline
\end{tabular}

Table 4.3: Correlations of SAR data vs numerical refraction model for top hat current profile.

edges. The correlation improvement from the symmetric jet to the asymmetic jet shape indicates that the velocity may be slightly skewed towards the North Wall.

The current direction which provides the best fit with the SAR data seems to be between $70^{\circ}$ and $75^{\circ}$. The southern boundary of the Gulf Stream is oriented at about $75^{\circ}$, so this value is reasonable. The $U_{\max }$ which provides the best correlation is 2.25 $\mathrm{m} / \mathrm{s}$ for the symmetric jet current profile, $2.5 \mathrm{~m} / \mathrm{s}$ for the asymmetric jet current profile, and $2.0 \mathrm{~m} / \mathrm{s}$ for the top hat profile.

There is a fair amount of data scatter both before and within the Gulf Stream. This makes it difficult to assign a specific meaning to a pair of data points which digress from the trend followed by the rest. However, both the wave length and angle of propagation show two data points within the Gulf Stream which differ significantly from a smooth curve. This could be indicative of an eddy formation or lateral variability within the Gulf Stream at this point; the length scale is between $6 \mathrm{~km}$ and $12 \mathrm{~km}$. 


\section{Chapter 5}

\section{Summary and Conclusions}

Ocean waves which interact with currents in deep water undergo refraction, and characteristics of the waves like length and height are affected by the interaction. This type of refraction can be observed, as swell propagates through major current systems like the Gulf Stream or the Antrarctic Circumpolar Current. A model which examines wave-current kinematics can be used in conjunction with remote sensing measurements of wave propagation to infer the current system which caused the measured refraction.

The study of the kinematics of wave-current refraction really involves two problems: (1) the direction of wave propagation, and (2) the changes in wave length. The wave orthogonals (perpendicular to wave crests) follow paths tangent to the wave number vector at a phase speed modified by current interactions. This is the direction of propagation seen by an external observer who takes a 'snapshot' of the wave system. The wave ray gives the direction of energy propagation traveling at the group velocity and is given by the vector sum of the intrinsic group velocity and the current velocity.

A numerical model is developed which predicts the direction of propagation and wave length, as a wave ray or orthogonal is refracted by a current. This model is validated by comparing its results to analytical solutions for cases of simple refraction problems.

SEASAT SAR data from a pass over the Gulf Stream are analyzed to allow wave energy propagation to be traced across the Gulf Stream. The digitally processed SAR images are sectioned into overlapping $512 \times 512$ pixel frames. These frames are normal- 
ized, and a Fast Fourier Transform is performed on each one. The magnitude of the transform is found, and it is oriented with the zero wave number at the center. The resulting raw spectra are smoothed and trimmed to obtain energy spectra which show waves of length greater than $50 \mathrm{~m}$. These spectra contain energy peaks which correspond to a $200 \mathrm{~m}$ wave system which traveled from southeast to northwest across the Gulf Stream. The peaks are distinctly visible before and after the Gulf Stream, but within the Gulf Stream the waves are refracted into azimuth, and the effect of azimuth or Doppler smearing makes it much more difficult to trace the wave energy propagation.

The general position and width of the Gulf Stream below the satellite pass is clearly marked in the SAR images. Three possible current profiles are proposed to model the Gulf Stream: a symmetric jet, an assymetric jet, and a top hat. The current direction is modeled by directions of flow which vary from $60^{\circ}$ to $75^{\circ}$, and the current velocity, $U_{\max }$, is varied from 1.5 to $2.5 \mathrm{~m} / \mathrm{s}$. These current parameters are input into the numerical model as a current field. Using the model, the kinematics of a $200 \mathrm{~m}$ wave passing through the Gulf Stream are examined. The model output is compared to the SAR data by colocating the model with the data by representing the wave length and direction of propagation as sets of vectors. From this the magnitude and phase angle of the complex correlation between the SAR data and the model are calculated. The wave length and angle residuals are also calculated to provide an additional measure for comparison.

The best correlations are found for Gulf Stream velocities between 2.0 and $2.5 \mathrm{~m} / \mathrm{s}$ at $70^{\circ}$ to $75^{\circ}$. The best overall correlation between the model and SAR data is obtained when the Gulf Stream is modeled by a top hat profile, a velocity of $2.0 \mathrm{~m} / \mathrm{s}$, and a direction of $75^{\circ} .75^{\circ}$ agrees with the direction visually observed from the SAR images, and the direction and speeds are close to the Coast Guard estimates for the Gulf Stream on this day. The current profiles used in the model do not take into account a possible widening of the Gulf Stream at the position of the satellite overpass. There is a great deal of scatter in the SAR data both before and in the Gulf Stream, so it is difficult to correlate every point with specific current behavior, but the increase in wave length and change in angle in the center of the Gulf Stream seem to indicate that there may be a non-uniform feature such as an eddy or lateral variation forming within the current. 
SAR data can be used to trace wave systems which pass through a current like the Gulf Stream. The tomographic employment of SAR data in conjunction with a numerical model for wave-current refraction can be used to infer the current which caused the wave refraction. In order for the approach described above to be practically useful, a uniform and stable long wave system must exist. This tomographic application requires a wave system which stays in the range direction with regard to the satellite, or which is long enough to still be measured in azimuth. The large scale current behavior is quite evident in the SAR data, but small scale eddies or lateral variations are harder to measure, because they may have smaller length scales than the scales of the frames processed here.

Lower flying SARs which overcome some of the inherent problems of azimuth smearing are superior to the SAR which flew in SEASAT for this type of tomographic application. Two Shuttle missions deployed SARs, the SIR-A and SIR-B flights; they provided relatively short sets of SAR data from lower altitudes than SEASAT. Even SARs deployed in high flying aircraft can provide wide geographic coverage of current systems.

SAR and numerical models of wave-current refraction offer promising new tools to the oceanographer, as he seeks to better measure and understand the ocean environment. When they are used together, the structure of current systems can be measured from space. This type of tomography is limited by azimuth smearing, as a wave system is refracted out of the range and into the azimuth direction. Lower flying SARs which will overcome azimuth smearing and also provide better small scale resolution are needed to continue this area of oceanographic research. 


\section{Bibliography}

Abernethy, C.L. and Gilbert,G., 1975: Refraction of Wave Spectra. Rep No. INT 117, Hydraulics Research Station, Wallingford Oxfordshire, UK., 87 pp.

Arthur, R.S., 1950: Refraction of Shallow Water Waves: the Combined Effect of Currents and Underwater Topography. Transactions of the American Geophysical Union. 31 (4), 549-552.

Beal, R.C., D.G. Tilley, and F.M. Monaldo, 1983: Large and Small Scale Evolution of Digitally Processed Ocean Wave Spectra From SEASAT Synthetic Aperture Radar. Journal of Geophysical Research. 88 (C3), 1761-1778.

Beal, R.C., T.W. Gerling, D.E. Irvine, F.M. Monaldo, and D.G. Tilley, 1986: Spatial Variations of Ocean Wave Directional Spectra From the SEASAT Synthetic Aperture Radar. Journal of Geophysical Research. 91 (C2), 2433-2449.

Brampton, A.H, 1977: A Computer Method for Wave Refraction. Hydraulics Research Station, Wallingford Oxfordshire, UK., 37 pp.

Chao, Y.Y., 1972: Refraction of Ocean Surface Waves on the Continental Shelf. Proceedings of the Fourth Offshore Technology Conference. OTC 1616, 965-976.

Earle, M.D. and O.S. Madsen, 1987: Wave Climate. Georges Bank. MIT Press, Cambridge, Mass, 78-86.

Graber, H.C., M.W. Byman, and W. Rosenthal, 1989: Numerical Simulation of Surface Wave Refraction in the North Sea. Part 1: Kinematics. Submitted to Deutsche Hydrographische Zeitschrift.

Graber, H.C., and K.A. Kelly, 1988: Principles and Physics of Remote Sensing in Oceanography. Lecture Notes in MIT/WHOI Joint Program in Oceanography and Oceanographic Engineering, 357 pp.

Johnson, J.W., 1947: The Refraction of Surface Waves by Currents. Transactions of the American Geophysical Union. 28 (6), 867-874.

Kenyon, K.E., 1971: Wave Refraction in Ocean Currents. Deep Sea Research. 18, 10231034. 
Kingsman, B., 1965: Wind Waves: Their Generation and Propagation on the Ocean Surface. Prentice Hall, Eaglewood Cliffs, N.J., 676 pp.

Kundu, P.K., 1975: Ekman Veering Observed Near the Ocean Bottom. Journal of Physical Oceanography. 6, 238-242.

Longuet-Higgins M.S. and R.W. Stewart, 1960: The Changes in Amplitude of Short Gravity Waves on Steady Non-Uniform Currents. Journal of Fluid Mechanics. 8, 565-583.

Mapp, G.R., C.S. Welch, and J.C. Munday, 1985: Wave Refraction by Warm Core Rings. Journal of Geophysical Research. 90 (C4), 7153-7162.

Monaldo, F.M., and D.R. Lyzenga, 1986: On the Estimation of Wave Slope- and HeightVariance Spectra from SAR Imagery. IEEE Transactions on Geoscience and Remote Sensing. GE-4. 4. 543-551.

Pararas-Carayannis, G., G.R. Miller, and J. Pararas-Carayannis, 1968: Numerical Calculations of Wave Refraction Using Plane Triangles as the Approximation to the Velocity Surface. Transactions of the American Geophysical Union. 49 (1), 210.

Philips, O.M., Dynamics of the Upper Ocean. Cambridge University Press, N.Y., 2nd Edition, 336 pp.

Treloar, P.D., 1985: Spectral Wave Refraction Under the Influence of Depth and Current. Coastal Engineering. 9, 439-452.

Unna, P.J.H., 1942: Waves and Tidal Streams. Nature. 149, 219-220.

Williams, J., J.J. Higginson, and J.D. Rohrbough, 1975: Sea and Air. Naval Institute Press, Annapolis, Md., 338 pp. 